\title{
Advanced concept for a crewed mission to the Martian moons
}

\author{
Davide Conte $^{\mathrm{a}, 1}$, Marilena Di Carlo ${ }^{\mathrm{b}}$, Dorota Budzyń ${ }^{\mathrm{c}}$, Hayden Burgoyne ${ }^{\mathrm{d}}$, \\ Dan Fries ${ }^{\mathrm{e}}$, Maria Grulich ${ }^{\mathrm{f}}$, Sören Heizmann ${ }^{\mathrm{g}}$, Henna Jethani ${ }^{\mathrm{h}}$, Mathieu \\ Lapôtre $^{\mathrm{i}}$, Tobias Roos ${ }^{\mathrm{j}}$, Encarnación Serrano Castillok ${ }^{\mathrm{k}}$, Marcel Schermann ${ }^{\mathrm{f}}$, \\ Rhiannon Vieceli ${ }^{1}$, Lee Wilson ${ }^{\mathrm{i}}$, Christopher Wynard $^{\mathrm{m}}$ \\ ${ }^{a}$ The Pennsylvania State University, 229 Hammond Bldg, University Park, PA 16802, USA \\ ${ }^{b}$ University of Strathclyde, 16 Richmond St, Glasgow G1 $1 X Q, U K$ \\ ${ }^{c}$ ESA/EAC, Linder Höhe, 51147 Cologne, Germany \\ ${ }^{d}$ Analytical Space, Inc., Boston, MA, USA \\ ${ }^{e}$ Georgia Institute of Technology, North Ave NW, Atlanta, GA 30332, USA \\ ${ }^{f}$ ESA/ESTEC, Keplerlaan 1, 2201 AZ Noordwijk, Netherlands \\ ${ }^{g}$ Universität Stuttgart, Keplerstraße 7, 70174 Stuttgart, Germany \\ ${ }^{h}$ Blue Origin, 21218 76th Ave $S$ Kent, Washington 98032, USA \\ ${ }^{i}$ California Institute of Technology, 1200 E California Blvd, Pasadena, CA 91125, USA \\ ${ }^{j}$ Lulea University of Technology, Space Campus, 98128 Kiruna, Sweden \\ ${ }^{k}$ Università di Bologna, Via Fontanelle 40, 47121 Forlì (FC), Italy \\ ${ }^{l}$ New Mexico Institute of Mining and Technology, 801 Leroy Pl, Socorro, NM 87801, USA \\ ${ }^{m}$ NASA Johnson Space Center, 2101 E NASA Pkwy, Houston, TX 77058, USA
}

\begin{abstract}
This paper presents the conceptual design of the IMaGInE (Innovative Mars Global International Exploration) Mission. The mission's objectives are to deliver a crew of four astronauts to the surface of Deimos and perform a robotic exploration mission to Phobos. Over the course of the 343 day mission during the years 2031 and 2032, the crew will perform surface excursions, technology demonstrations, In Situ Resource Utilization (ISRU) of the Martian moons, as well as site reconnaissance for future human exploration of Mars. This mission design makes use of an innovative hybrid propulsion concept (chemical and electric) to deliver a relatively low-mass reusable crewed spacecraft (approximately $100 \mathrm{mt}$ ) to cis-martian space. The crew makes use of torpor which minimizes launch payload mass. Green technologies are proposed as a stepping stone towards minimum environmental impact space access. The usage of
\end{abstract}

\footnotetext{
${ }^{1}$ Corresponding author. Email address: davide.conte90@gmail.com
} 
beamed energy to power a grid of decentralized science stations is introduced, allowing for large scale characterization of the Martian environment. The lowthrust outbound and inbound trajectories are computed through the use of a direct method and a multiple shooting algorithm that considers various thrust and coast sequences to arrive at the final body with zero relative velocity. It is shown that the entire mission is rooted within the current NASA technology roadmap, ongoing scientific investments and feasible with an extrapolated NASA Budget. The presented mission won the 2016 Revolutionary Aerospace Systems Concepts - Academic Linkage (RASC-AL) competition.

Keywords: Mars, Phobos, Deimos, Human Exploration, Martian Moons, Mars Mission

\section{Introduction}

Space exploration enriches and strengthens humanity's future by bringing nations together for a common cause; it reveals knowledge, inspires and educates people, creates a global partnership, establishes a sustained human pres5 ence in the Solar System, and stimulates technical and commercial innovation on Earth. Sustainable space exploration is a challenge that no single nation can do on its own. To this aim, the Global Exploration Strategy, which was agreed on and published in May 2007 by fourteen space agencies, reflects a determination to explore our nearest neighbors: the Moon, asteroids, and Mars. In this framework, the Dream Team has been created with young engineering and applied science students from all over the world with a common goal, the IMaGInE Mission.

Previous missions to any body outside of the Earth-Moon sphere of influence have been limited to robotic missions. While such systems are superior to humans in certain areas, they cannot yet compete with human adaptability and intuition. Moreover, human presence is required to initiate an outpost and lay the foundation for human settlement and utilization of other planetary bod- 
ies. Nonetheless, human-robot cooperation will most likely maximize chances of success of this endeavor and, thus, the overarching requirements of the mission as stated by RASC-AL are: "Given a 20 year timespan starting in 2015, and a flat total NASA budget of $\$ 16$ Billion a year, derive an architecture that delivers a crew of four to the surface of either Phobos or Deimos (or both) for a minimum of 300 days total. Lay out a series of Mars moons surface excursions driven by science, technology demonstration, ISRU and possible future human exploration site reconnaissance on Mars. The architecture will convey a series of missions, both robotic and crewed, that will capture the exploration of one or both of the Martian moons, and must include tele-operating Mars surface assets (i.e., rovers, ISRU production plants, infrastructure cameras, small Mars flyers, so deployment of power and support systems, etc.) while the astronauts are not conducting Extravehicular Activities (EVAs). All existing NASA programs will continue with some reduction in annual funding allowed (maintain at least $80 \%$ of their current budget), but the total NASA budget will remain flat, adjusting for inflation."

To fulfill these requirements the Dream Team started with a rigorous analysis of technology options, existing technology roadmaps, as well as astrodynamics, time and financial constraints. The result is a reusable architecture designed to ferry astronauts between planetary bodies, utilizing a chemical-electric hybrid 40 propulsion concept and re-supply missions from Earth. During the entire mission duration a total mass of $340 \mathrm{mt}$ is launched into Low-Earth-Orbit (LEO) with 6 launches including crewed, test, and resupply missions. Maximizing the synergies with existing programs, the total cost is well within the projected NASA budget, at B $\$ 32$ (FY2016) over 20 years. While some of the proposed 45 technologies do not exist yet at a sufficient Technology Readiness Level (TRL), it was made sure that they are realistic options with regard to funding, current interest and scheduling. A preliminary risk analysis shows that the presented architecture minimizes the risk of loss of crew and loss of mission. 
Key aspects to minimize the overall launch mass, number of launches, and impact of the Earth-Mars transit on the crew are highly optimized trajectories, artificially induced torpor [1] of the crew and a development schedule accounting for sufficient tests of the life support system and the spacecraft as a whole. During the mission robotic exploration of Deimos, Phobos and Mars itself are conducted. Moreover, ISRU is tested, which is a key enabling technology for future deep space missions and anything resembling an interplanetary economy [2]. The science mission introduces a satellite based beamed power concept [3] which powers a grid of 54 decentralized science stations on Mars. This will allow for an unprecedented amount of detail in charting large parts of the Martian geography and environment over long periods of time. Thus, progressing our understanding of a different world as well as our efforts for colonization and extraction of resources.

\section{Mission Architecture and Test Mission}

The IMaGInE mission will deliver a crew of four astronauts to the surface of Deimos and a robotic exploration mission to Phobos for approximately 343 days during the years 2031 and 2032. The crew will perform surface excursions, technology demonstrations, and In Situ Resource Utilization (ISRU) of the Martian moons as well as site reconnaissance for future human exploration of Mars. The IMaGInE Mission is divided into two main segments: the test mission and the main mission. The test mission first provides the opportunity to test all of the major subsystems combined together in space, thus raising the overall system's Technology Readiness Level (TRL). Additionally, the test mission substantially lowers the risk the main mission crew incurs and leaves the science portion of the mission untouched. A summary of IMaGInE's mission architecture is depicted in Figure 1. This diagram also shows when and where supplies are replenished (REV-1, REV-2, REV-3, REV-4). The mission architecture is explained in detail in the following paragraph. Deimos was chosen over Phobos for the crewed portion of the mission primarily because of the 


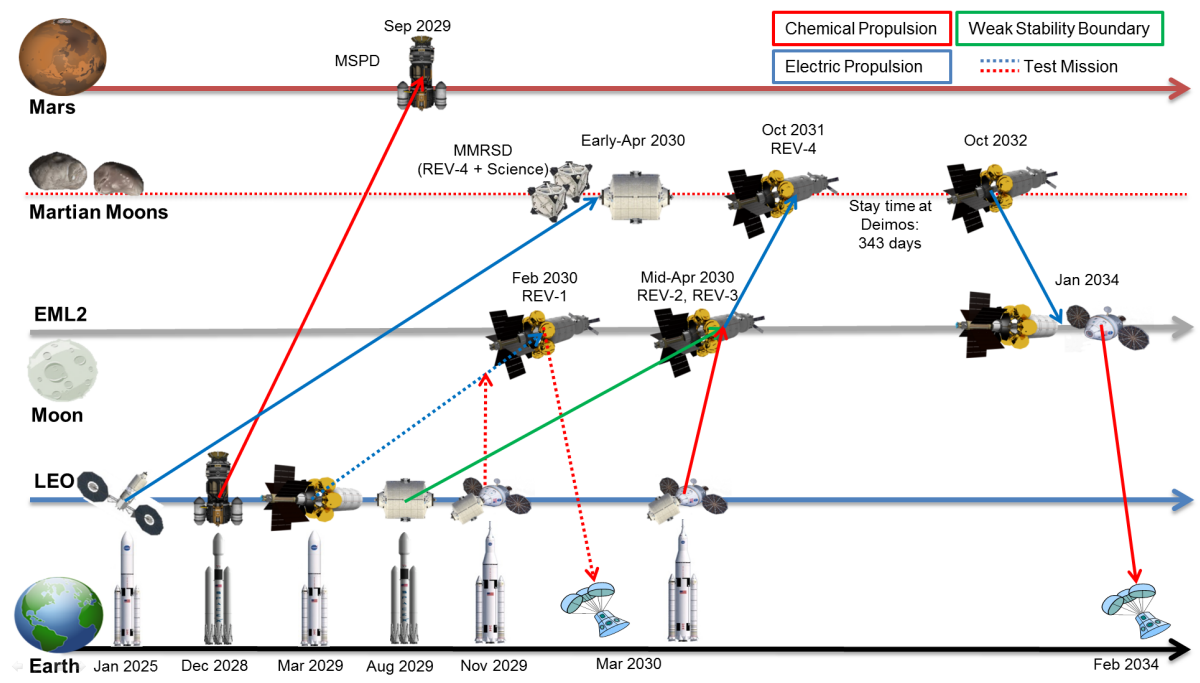

Figure 1: IMaGInE's mission architecture.

moon's accessibility (lower $\Delta \mathrm{V}$ requirements and better access to the subsurface), better illumination conditions, and longer communication passes to sites on Mars. The Phobos vs. Deimos trade study is shown in Table A.9.

The first launch takes the Martian Moons Resupply and Science Deployment (MMRSD) vehicle into Low Earth Orbit (LEO) in January 2025. This launch 85 is performed using a NASA Space Launch System (SLS) Block 1B from the Kennedy Space Center (KSC) and consists of a Resupply Expendable Vehicle (REV) that is pre-deployed at Deimos to ensure that the crew has enough supplies to conduct scientific exploration of the Martian system (Mars, Phobos, and Deimos). Along with resupply vehicle REV-4, a science payload is to be delivered at Phobos and Deimos. More details about the scientific part of the mission can be found in Section 9, Science and Robotics. MMRSD consists of an Asteroid Redirect Mission (ARM)-derived propulsion system with a Multi-Purpose Logistics Module (MPLM)-derived module (REV-4) containing supplies for the crew. The spacecraft performs a low-thrust interplanetary transfer (Figure F.14 95 in Appendix F) and arrives in an orbit similar to that of Deimos in early April 
2030. Note that although MMRSD is launched relatively early compared to the other launches, it reuses technologies that would be available for ARM in the early 2020s.

In December 2028, a Falcon Heavy is launched from KSC carrying scientific Earth's surface in mid-November 2029. This altitude was chosen to perform the rendezvous of the two spacecraft because it minimizes the time the test crew spends in the Van Allen Belts radiation region. While the mothership takes 252 days to arrive at $60,000 \mathrm{~km}$, the crew uses Orion's main engine to arrive at Orion capsule and a resupply module, REV-1, that carries resupplies for the mothership for the test mission (Figure 2).

Once the test crew arrives at the mothership and the resupply has been completed, REV-1 is discarded and the mothership + test crew in Orion continue grange Point 2 (EML2). Here, the spacecraft completes an insertion maneuver into a halo orbit about EML2, denoted as EML2, in February 2030. At this point the test crew undocks from the mothership and performs a lunar flyby to return to Earth in approximately 10 days. At the end of the test missions, 125 data collected on system performance and crew-system interaction is evaluated to identify any remaining issues and allow for the implementation of improve- 


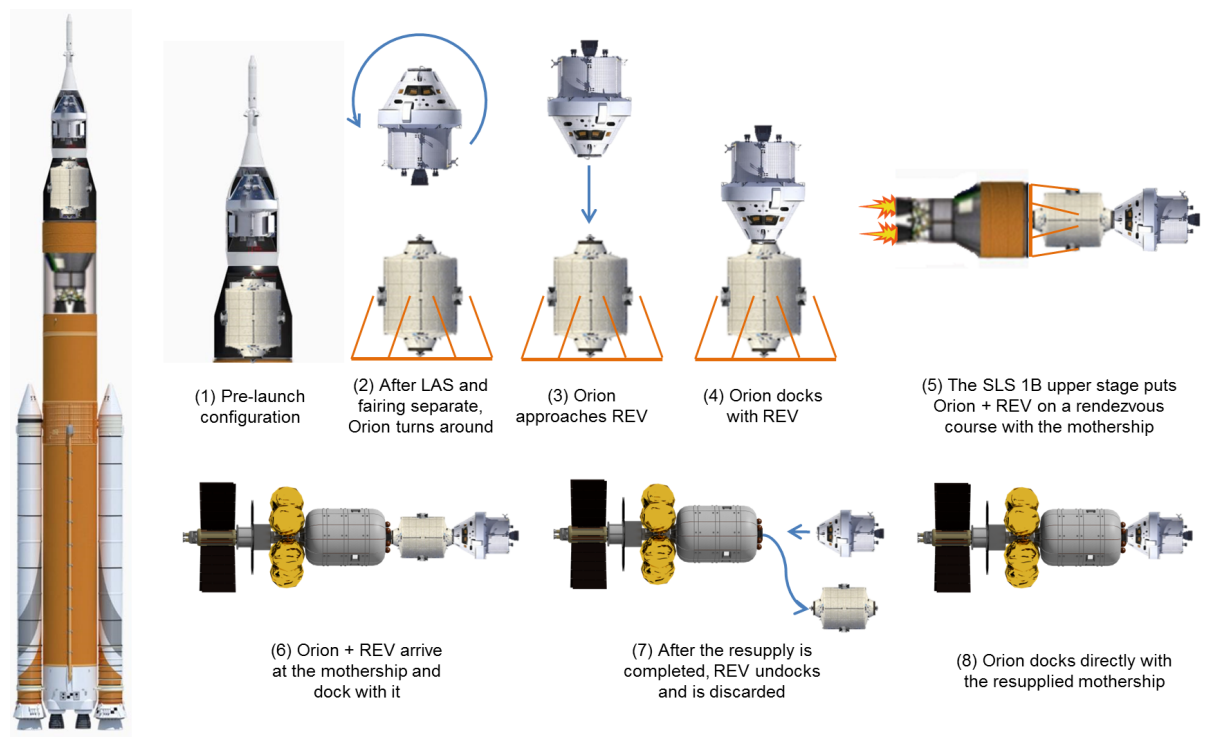

Figure 2: Main phases of the first two Resupply Expendable Vehicles, REV-1 and REV-2.

ments and repairs before the commencement of the main mission. In fact, the test mission is used as a benchmark to see how the mothership and all of its systems perform. The main mission begins in March 2030, when possibly a new crew launches on board of Orion with an SLS Block 1B from KSC, bringing a second resupply spacecraft, REV-2, capable of resupplying the mothership in a similar way done by the test crew (Figure 2), this time at EML2. A third resupply mission (REV-3), which is delivered by a Falcon Heavy on a Weak Stability Boundary (WSB) trajectory, arrives and prepares the mothership for the journey to Deimos (resupply procedure shown in Figure 3 .

In mid-April 2030, the mothership + Orion depart EML2, performing an interplanetary low-thrust maneuver, and arrive in the Martian Sphere of Influence (SOI) in late August 2031. The spacecraft arrives at Deimos in October 2031 where the crew performs the fourth resupply mission (REV-4) which was pre-deployed by MMRSD (resupply procedure shown in Figure 33). Once the resupply takes place, scientific operations ensue for approximately 340 days. In October 2032, the crew departs from Deimos and returns to Earth's SOI in Jan- 


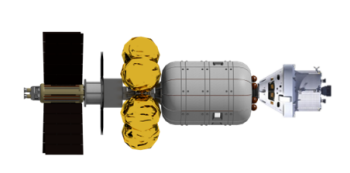

(1) The mothership and Orion are docked

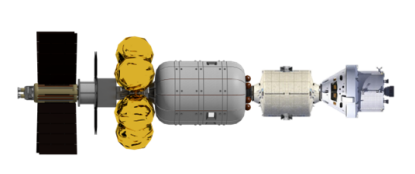
(4) Orion + REV dock with
the mothership

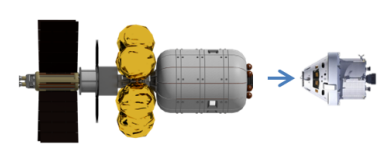

(2) Orion undocks from the mothership

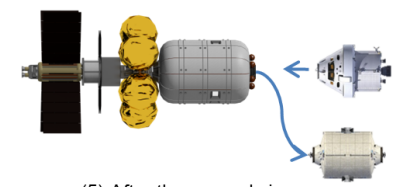

(5) After the resupply is

and is discarded

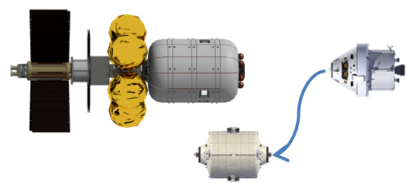

(3) Orion docks with REV

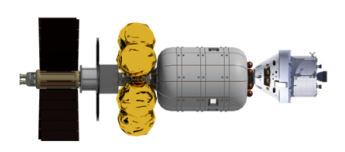

(6) Orion docks directly with

Figure 3: Main phases of the second two Resupply Expendable Vehicles, REV-3 and REV-4.

uary 2034. Upon arrival in Earth's SOI, the crew separates on board Orion and performs a direct re-entry, while in late January 2034 the mothership returns to EML2 for future resupply and reuse. A computer-generated model of the entire spacecraft is visible in Appendix G. For a short animation of the proposed mission concept, refer to the mission video [4].

Note that each REV is fitted with two docking ports located on opposite ends of the vehicle so that one docks with the mothership and the other docks with Orion. Having two docking ports on each REV avoids having to depressurize and re-pressurize Orion. The resupply procedure utilized by REV-1 and REV-2 is shown in Figure 2 while that used by REV-3 and REV-4 is shown in Figure 3 Additionally, REV-1, REV-2, and REV-4 are MPLM-derived spacecraft while REV-3 consists of a smaller ATV-derived module.

\section{Mission Analysis}

In order to accomplish the mission, the mothership's main propulsion system is a series of four Variable Specific Impulse Magnetoplasma Rockets (VASIMR) which are powered by a series of Safe Affordable Fission Engines (SAFE-400) [5] 6]. In order to shield the crew from the SAFE-400s on board, additional reactor shielding based on the X-ray telescope Chandra is used. This is composed of slightly curved mirrors that are used to diffract X-rays away from 
HARMONIA [7. More details regarding radiation shielding can be found in Section Compared to chemical and nuclear propulsion, using electric propulsion reduces the required Initial Mass in LEO (IMLEO) for round trips to Mars by at least one order of magnitude. Chemical propulsion is only used to reduce the Time of Flight (ToF) of the crew from LEO to EML2 at departure and from EML2 to LEO at arrival. IMaGInE's architecture is developed with the idea of making missions to the Martian system sustainable and cost-efficient. In fact, the mothership is kept in EML2 for future missions. EML2 was chosen as the staging location for the mission because it allows constant communication and is a favorable energetic orbit relatively close to Earth, from which the crew can return to Earth and to which the crew can easily arrive in at most 10 days using chemical propulsion. Figures 4 and 5 show the crewed interplanetary outbound and inbound trajectories where green and red symbolize coasting and thrusting, respectively. Details regarding the method adopted for computing such orbits is described in Appendix E. Additionally, MMRSD's interplanetary trajectory is shown in Figure F.14 in Appendix F. Details regarding all of the major subsystems of IMaGInE are given in the following sections. Table 1 summarizes the main phases of the entire mission.

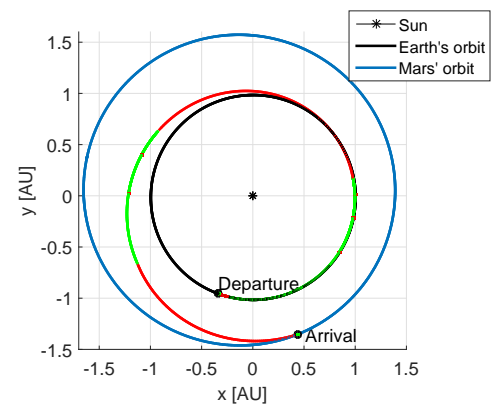

Figure 4: Earth-Mars. IMaGIne's interplanetary low-thrust outbound trajectory to Mars.

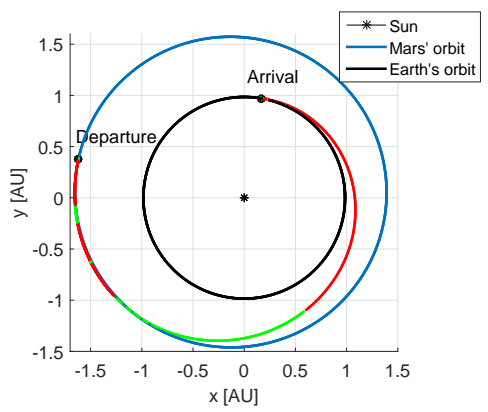

Figure 5: Mars-Earth. IMaGIne's interplanetary low-thrust inbound trajectory to Earth. 
Table 1: Mission analysis design parameters including margins. ${ }^{*} \mathrm{U}=$ Uncrewed; $\mathrm{TC}=$ Test Crew; $\mathrm{MC}=$ main Mission Crew.

\begin{tabular}{|c|c|c|c|c|c|c|}
\hline Mission Phase & $\begin{array}{r}\text { Initial } \\
\text { Mass }[\mathrm{mt}]\end{array}$ & $\begin{array}{c}\text { Final } \\
\text { Mass }[\mathrm{mt}]\end{array}$ & $\begin{array}{r}\text { Depart } \\
\text { Date }\end{array}$ & $\begin{array}{r}\text { Arrive } \\
\text { Date }\end{array}$ & $\begin{array}{c}\text { ToF } \\
\text { [days] }\end{array}$ & $\begin{array}{r}\Delta \mathrm{V} \\
{[\mathrm{m} / \mathrm{s}]}\end{array}$ \\
\hline LEO - Deimos (MMRSD) & 84.80 & 56.60 & 28 Jan 2025 & 1 Apr 2030 & 1889 & 11413 \\
\hline LEO - Mars (MSPD) & 54.40 & 13.60 & 18 Dec 2028 & 3 Sep 2029 & 259 & 3567 \\
\hline LEO - $60000 \mathrm{~km}(\mathrm{U})$ & 99.91 & 89.90 & 6 Mar 2029 & 13 Nov 2029 & 252 & 5279 \\
\hline LEO - EML2 (REV-3) & 11.30 & 11.30 & 1 Aug 2029 & 1 Apr 2030 & 243 & $\tilde{3} 200$ \\
\hline LEO - $60000 \mathrm{~km}(\mathrm{TC}+\mathrm{REV}-1)$ & 45.00 & 45.00 & 11 Nov 2029 & 13 Nov 2029 & $1-2$ & 4092 \\
\hline 60000 km - EML2 (TC) & 138.04 & 133.95 & 13 Nov 2029 & 24 Feb 2030 & 103 & 1503 \\
\hline EML2 - Earth (TC) & 27.09 & 27.09 & 24 Feb 2030 & 6 Mar 2030 & $\sim 10$ & 390 \\
\hline LEO - EML2 (MC+REV-2) & 45.00 & 45.00 & 16 Mar 2030 & 26 Mar 2030 & $\sim 10$ & 4092 \\
\hline Stay at EML2 (MC) & 137.38 & 135.82 & 26 Mar 2030 & 15 Apr 2030 & 20 & - \\
\hline EML2 - SOI Earth (MC) & 135.82 & 133.93 & 15 Apr 2030 & 1 June 2030 & 47 & 700 \\
\hline SOI Earth - SOI Mars (MC) & 133.93 & 124.43 & 1 Jun 2030 & 30 Aug 2031 & 455 & 3677 \\
\hline SOI Mars - Deimos (MC) & 124.43 & 122.06 & 30 Aug 2031 & 29 Oct 2031 & 60 & 965 \\
\hline Stay at Deimos (MC) & 136.34 & 109.53 & 29 Oct 2031 & 6 Oct 2032 & 343 & - \\
\hline Deimos - SOI Mars (MC) & 109.53 & 107.44 & 6 Oct 2032 & 27 Nov 2032 & 53 & 965 \\
\hline SOI Mars - SOI Earth (MC) & 107.44 & 99.23 & 27 Nov 2032 & 1 Jan 2034 & 400 & 3973 \\
\hline SOI Earth - EML2 (U) & 61.74 & 60.88 & 1 Jan 2034 & 23 Jan 2034 & 22 & 700 \\
\hline SOI Earth - Earth (MC) & 27.09 & 27.09 & 23 Jan 2034 & 2 Feb 2034 & $\sim 10$ & $\sim 400$ \\
\hline
\end{tabular}

\section{Propulsion and Electrical Power System}

To find an appropriate propulsion technology capable of bringing a spacecraft of more than 50 metric tons to a Martian moon and back $(\Delta \mathrm{v}>12000$ $\mathrm{m} / \mathrm{s}$ ), a trade-off was carried out for the three most promising and realistic technologies: chemical, nuclear and electrical (see Table A.10 in Appendix A). For this purpose, the two major characteristics of a propulsion technology, specific impulse $\left(I_{s p}\right)$ and thrust, have been taken into account. $I_{s p}$ is responsible for the payload fraction of a rocket and for the necessary IMLEO of an interplanetary spacecraft, while the thrust is mainly responsible for the time of flight of an interplanetary trajectory. By comparing these factors as well as TRL and safety of each technology, the most promising solution can be found. As a result of this trade-off, an electrically propelled spacecraft was found to be the best 
option.

In order to bring such a mass into cis-martian space, a chemically propelled spacecraft would require either an infeasibly high IMLEO, or an impractical number of launches. Nuclear propulsion has better performances with respect to a chemical solution in terms of payload fraction and IMLEO but has disadvantages in terms of TRL and safety. On the contrary, an electrically propelled spacecraft has the lowest IMLEO and gives the most mass efficient and safe solution that can be launched into LEO despite having the lowest thrust and therefore the longest ToF, which has an unfavorable effect on the crew.

It can be seen that there is a trade-off between low IMLEO and low ToF. This suggests that chemical propulsion should be used for mission phases where the time of flight is most critical (i.e. crew transport), while electric propulsion should be used where IMLEO is most important (i.e. cargo transport). This leads to the concept of using electric propulsion for the mothership and using chemical propulsion to send the crew quickly and as far as possible towards Mars. Since EML2 can be reached by chemical propulsion in a quite short time and has an orbit with a high characteristic energy, it provides an appropriate place to dock the crewed spacecraft with the mothership. Thereby, the overall IMLEO can be drastically reduced while keeping the ToF for the crew at a reasonable length. This means that the crew will spend roughly one third of the whole mission time at Deimos. As a consequence, the concept that was implemented for IMaGInE was achieved by using both chemical and electrical technologies. This gives the outstanding possibility of keeping the IMLEO of a crewed interplanetary spacecraft in the range of the payload capability of a single SLS 1B and simultaneously reducing the mission duration for the astronauts by more than one year, compared to a solely electrical concept.

To implement this concept, four VASIMR engines are used to propel the moth220 ership. These engines have one of the highest $I_{s p}$ (5096 s) and thrust (5.76 N) of all electric engines currently in development [5]. Due to the fact that each engine requires $200 \mathrm{~kW}$ of electrical power, a powerful Electrical Power System (EPS) is necessary. To find the most suitable technology for the EPS, 
a trade-off has been conducted. Table A.11 in Appendix A shows that an EPS based on a nuclear technology is the best choice for the mission. This is mainly due to the very high weight specific power production and to the fact that the distance of the spacecraft to the Sun has no influence on power generation. For comparison, the solar constant decreases from Earth $\left(1.367 \mathrm{kWm}^{-2}\right)$ to Mars $\left(0.5897 \mathrm{kWm}^{-2}\right)$ by $57 \%$ and would therefore require solar panels with an area ${ }_{30}$ of almost $5 \mathrm{~km}^{2}$ to support four VASIMR engines. Moreover, the technology of nuclear fission reactors is already flight tested and it enables a high expandability of the EPS. This is important because the required energy of an electrically propelled spacecraft is particularly sensitive to the spacecraft mass. Regarding safety, the chosen SAFE-400 nuclear fission reactor is passively safe in all launch or re-entry accidents and keeps subcritical even without any control. Moreover, it is not radioactive before operation [6]. Therefore, the propulsion and EPS concept used by IMaGInE is also much safer than an NTR, despite both systems using nuclear technology.

\section{Systems Engineering}

All mass, power, and volume requirements, as well as costs, are assigned margins up to $20 \%$, based on TRL and specifications. Finally, a system-wide margin of $20 \%$ is added [8]. Design decisions are made in accordance to trade studies and well-defined subsystem requirements. The former are presented in Appendix A, while the latter can be traced to Top-Level (TL) requirements and competition Ground Rules (GR), which are given in Table B.16 and B.17in Appendix B. This allows for a complete assessment of the overall infrastructure, ensures fulfillment of the mission, and avoids over-design [8]. Based on derived requirements and NASA standards [9], a risk analysis has been performed to ensure failure modes have been mitigated (see Appendix C). The test schedule and development plans have been established based on TRL, launch manifest, and synergies with existing programs. The critical technologies, their estimated initial and targeted TRL, and the implementation of the development program 
are shown in Table 2, None of the used sources are older than 12 months to ensure all information is current.

Table 2: Development of critical technologies.

\begin{tabular}{|c|c|c|}
\hline Technology & TRL & Implementation \\
\hline ECLSS - Torpor & $3-8$ & $\begin{array}{l}\text { Currently under development with NASA } \\
\text { support [10]. Use in study similar to Mars } \\
500 \text { for testing (could involve ISS). }\end{array}$ \\
\hline $\begin{array}{l}\text { Science - Space Solar } \\
\text { Power }\end{array}$ & $4-8$ & $\begin{array}{l}\text { Currently under development by Caltech } \\
\text { and Northrop Grumman Corporation [11]. } \\
\text { Tests can be performed in LEO or with re- } \\
\text { gard to planned moon missions. }\end{array}$ \\
\hline Science - MAN Stations & $6-9$ & $\begin{array}{l}\text { Modified version of existing weather bal- } \\
\text { loons. }\end{array}$ \\
\hline Science - Moon Hoppers & $5-7$ & $\begin{array}{l}\text { Can be tested during ARM and Earth's } \\
\text { Moon robotic missions. }\end{array}$ \\
\hline $\begin{array}{l}\text { Deimos Science and } \\
\text { ISRU }\end{array}$ & $5-7$ & Can be tested during ARM. \\
\hline Mars Science and ISRU & $5-7$ & Can be tested during ARM. \\
\hline Propulsion - VASIMR & $3-8$ & $\begin{array}{l}\text { Currently under development with NASA } \\
\text { support [12] 13], with goal of testing the } \\
\text { engine on the ISS. }\end{array}$ \\
\hline $\begin{array}{l}\text { EPS - Safe- } 400 \text { Fission } \\
\text { Reactor }\end{array}$ & $3-7$ & $\begin{array}{l}\text { Basic technology exists. Most efforts have } \\
\text { to be expended to increase reliability and } \\
\text { safety. }\end{array}$ \\
\hline
\end{tabular}

The development schedule is shown in Figure 6 .

As human factors are of paramount importance, and a proposed, novel technology is expected to affect the crew, an extensive test environment is suggested, similar to the Mars500 experiment [14. This environment should be created to 


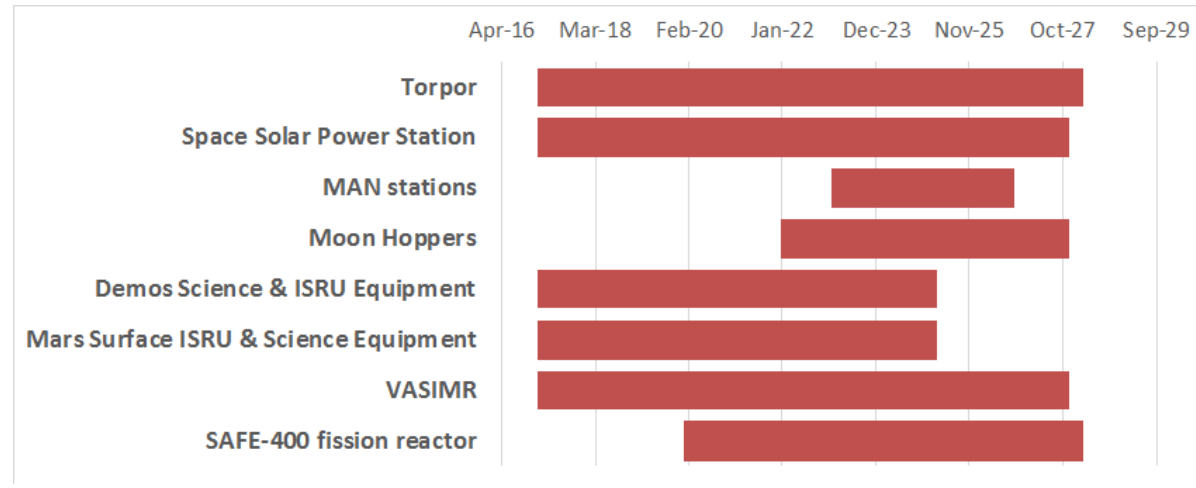

Figure 6: Schedule for the development program of critical technologies

show the feasibility of a continuously crewed mission lasting 3.6 years, test the continuous operation of the torpor units, test the torpor crew rotation cycles, study the effects on the astronauts, and determine the demand of maintenance required by the torpor units. Additionally, the mental stability of the conscious astronauts can be evaluated as well as the operational skills of the crew regarding the spacecraft after such a long time. The test environment runs from 2021 to 2025 . Thus, there would be 4 years during which to implement new knowledge and make adjustments to the actual mission before the test crew launches. The IMaGInE Mission will launch an overall total of 295.6 metric tons to conduct the proposed mission, using two Falcon Heavys and four SLS Block 1Bs. The science mission requires $10.4 \mathrm{t}$, which gives a margin of $27 \%$ on the launch capacity. The crewed mission requires an overall 287.4 t, which gives a margin of $10 \%$ on the launch capacity. Thus, the mass requirements are satisfied by the available launch capacity and $\Delta \mathrm{v}$. The volume requirements have been considered in the habitat and service-module design, and the power requirements are met by the SAFE-400 reactors and the Space Solar Power stations. Budget 275 summaries are given in Tables 3 and 4 
Table 3: Science Budget

\begin{tabular}{lrrr}
\hline & Mass $[\mathrm{t}]$ & Volume $\left[\mathrm{m}^{3}\right]$ & Power $[\mathrm{kW}]$ \\
\hline Total & 10.4 & 22.8 & 289.8 \\
Total $+20 \%$ & 12.4 & 27.4 & 347.8 \\
\hline Provided & 13.6 & 116 & 350 \\
\hline
\end{tabular}

Table 4: Crewed Mission Budget

\begin{tabular}{lrrr}
\hline & Mass [t] & Volume $\left[\mathrm{m}^{3}\right]$ & Power $[\mathrm{kW}]$ \\
\hline HERMES + HARMONIA & 155.7 & 149.7 & 482.5 \\
Orion & $2 \times 25.8$ & - & - \\
Resupply & 86 & - & - \\
\hline Total & 293.3 & 149.7 & 482.5 \\
Total $+20 \%$ & 351.96 & 179.6 & 579 \\
\hline Provided & 315.5 & 349.5 & 600 \\
\hline
\end{tabular}

\section{Attitude and Orbit Control System and Landing/Ascent at Deimos}

The main objective of the Attitude and Orbit Control System (AOCS) is to provide spacecraft navigation and orientation maneuver capabilities to point the spacecraft at desired targets based on mission requirements. AOCS is designed to minimize fuel consumption following the guidelines of the innovative risk-informed design process of NASA in order to design a vehicle with the best safety and reliability [15].

Propulsive maneuvers, crew activities, fuel slosh, and thruster misalignment are some disturbances that must be corrected to keep the desired attitude within an accuracy of $<0.1^{\circ}$ in each axis. This section presents a preliminary design of AOCS that complies to the requirements and constraints of the IMaGInE Mission and NASA-ESA standards. The mothership and Orion (with its service module) are both three-axis stabilized and are provided with a Failure Detection Isolation and Recovery (FDIR) system. Different AOCS modes of 
performance have been selected mainly depending on the mission phases and pointing requirements.

In order to determine the attitude of the spacecraft, different Commercially-offthe-Shelf (COTS) sensors have been chosen. Two sets of three Sun sensors (cold redundancy) by Honeywell have been selected. In terms of FDIR, the three Sun sensors are simultaneously on (hot redundancy). This ensures correct attitude determination should one unit fail. Primary and backup Inertial Measurement Units (IMUs) (Honeywell HG1900) measure changes to the spacecraft attitude as well as any non-gravitationally induced changes to its linear velocity. Each IMU is a combination of three accelerometers and three ring-laser gyroscopes. Two autonomous star trackers manufactured by Ball Aerospace are co-aligned at $90^{\circ}$ to provide 3 axis inertial attitude measurements used in cold redundancy. Trajectory Correction Maneuvers (TCMs) are performed mainly during orbital maneuvers for station-keeping purposes and momentum unloading. The actuators selected for this purpose are two sets of 4 Control Momentum Gyros (CMGs) and 32 Reaction Control System (RCS) thrusters capable to perform TCMs and fine attitude and orbit control maneuvers. A trade-off study among different types of thrusters to compare the performance of innovative and classical thruster technologies can be found in Table A.13 in Appendix A.

310 A pressure-fed integrated RCS using LOX and methane $\left(\mathrm{LCH}_{4}\right)$ thrusters has been selected. Aerojet 100-lbf thrust LOX/LCH 4 was selected due to its high $I_{s p}$ qualities (317 s), non toxicity, long term storability, suitability for ISRU and the possibility to use the crew's biowaste products [16].

\section{Landing and Ascent at Deimos}

315 The mothership + Orion will land on the surface of Deimos with a primary goal of landing precisely and safely. It will rest on a four-legged landing gear placed on Orion's service module (Figure 7). The spacecraft will include an innovative, autonomous navigation system that will be capable of landing without crew assistance and recognizing and avoiding hazards such as craters and boulders;

320 this system includes three Light Detecting And Ranging, or LiDAR, sensors and navigation cameras 17. The mothership will perform a soft-landing, and 
assuming uncertainties, only low impact velocities will occur at touch-down.

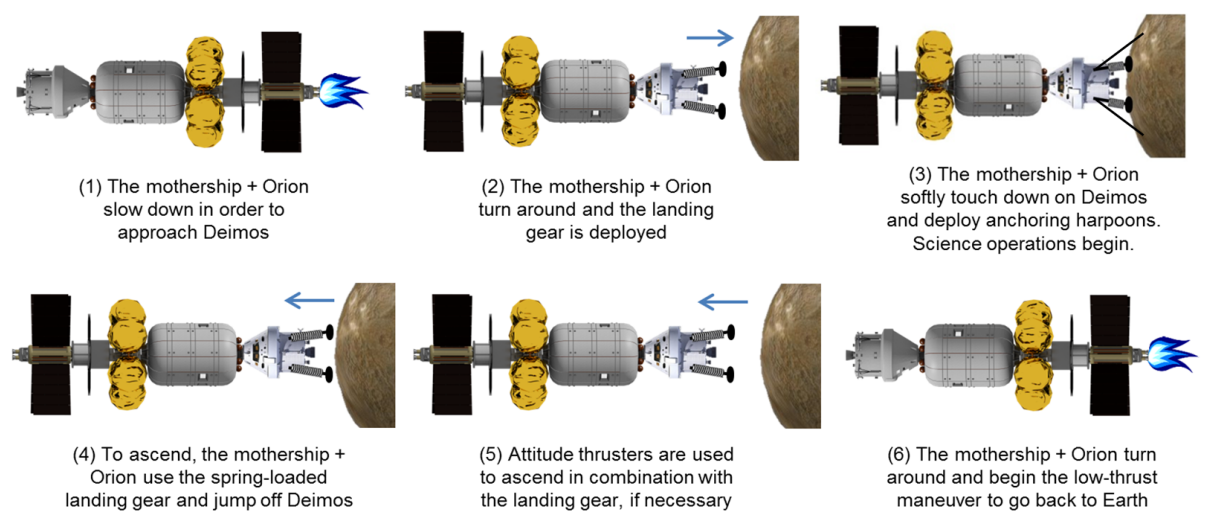

Figure 7: Main phases of the landing (1-3) and ascent (4-6) at Deimos.

While approaching Deimos, a $\Delta \mathrm{v}$ will be applied by HERMES to induce a near vertical descent the surface. The vertical thrusters will be turned off at an altitude of approximately $100 \mathrm{~m}$. From this point, just small thrust corrections will be performed down to an altitude of $10-20 \mathrm{~m}$, at which time it will have near-zero velocity. In order to prevent the thruster exhaust from contaminating Deimos regolith, the spacecraft will free fall from this point.

Due to Deimos' low gravity, re-bouncing becomes a significant issue and anchoring is required [18. Thus, the four landing legs will include ice-screws and an innovative damping system with the capability not only to smooth the impact, but also to store potential energy that can be used at the initial phase of the ascent. This is to prevent the use of RCS thrusters that could contaminate the moon's surface. Therefore, four anchoring ropes with harpoons will be fired to help keeping the local vertical. RCS is left as a backup solution in case the energy stored in the landing legs is not enough to reach escape velocity. HERMES' propulsion system has not been considered for ascent since the RCS thrusters give enough thrust for the ascent from Deimos. A trade-off concerning landing strategies is summarized in Table A.12 in Appendix A. 
7. Environmental Control and Life Support System and Human Factors

During the journeys to and from Deimos, crew members will make use of torpor. Torpor, which uses therapeutic hypothermia, allows the crew to enter an unconscious state of decreased body temperature and metabolic rate. Placing humans in this state reduces the consumption of life support resources, production of waste, and will avoid many of the psychological concerns associated with long-term spaceflight [1]. This reduction in consumables allows for significant mass savings. On average, a crew of four can save about $55 \mathrm{~kg}$ of consumables per day using torpor. Figure 8 shows the minimum, maximum, and average savings of consumables per day using torpor.

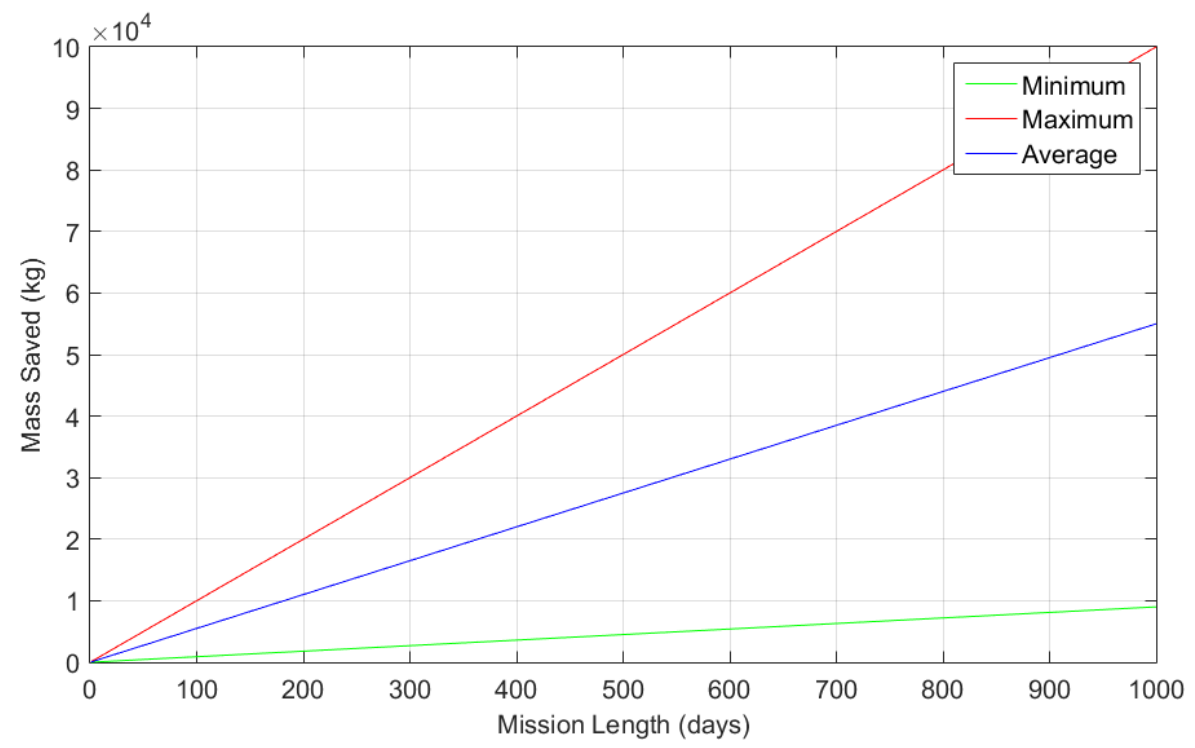

Figure 8: Torpor mass savings per day over mission duration.

During the course of the mission, astronauts will be placed in a rotating torpor state; all crewmembers will be awake for 4 days at a time followed by 5-11 days in a torpor state (including induction and awakening from torpor). During the trip to and from Deimos, one crew member will always be awake to manage communications with the ground, administer regular system checks, monitor 
crewmembers' vital signs, and aid in the torpor-induction and awakening of other crewmembers. In Figure 9, an example of the torpor schedule can be seen. Staggering torpor schedules as seen will allow for each crewmember to constantly be in the company of different crewmembers during their times awake. This will improve psychological states for each crewmember. Allowing each crewmember to be alone for part of a day during their active state will also prevent the stresses associated with constant companionship during the long mission to Deimos.

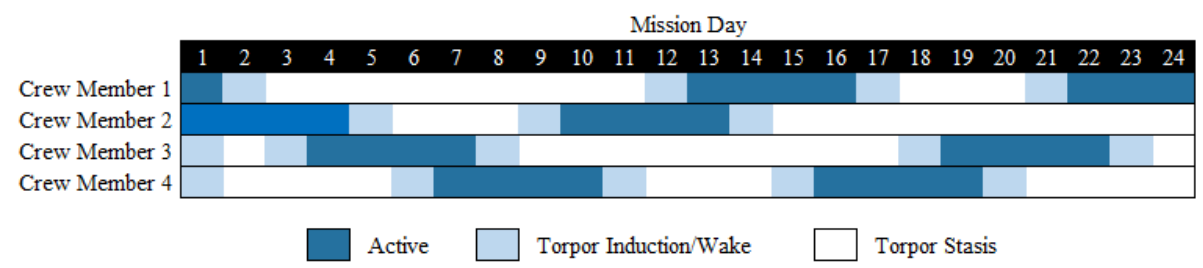

Figure 9: Torpor rotating schedule example

Risks associated with normal microgravity spaceflight including bone density loss and muscle atrophy can be mitigated through the use of pharmaceuticals and physical training in workout facilities on board HARMONIA. The risks and their associated mitigation techniques for the use of torpor are given in Table C.19 in Appendix C. The long mission to Deimos will require one crewmember to be a flight doctor. This crewmember will be able to track other crewmembers health during the mission. This will mitigate risks associated with torpor and ensure any sickness or injury can be taken care of on-board the spacecraft. Human patients that have undergone multiple cycles of therapeutic hypothermia showed no negative effects from the cyclic procedure in short-term or long-term timeframes 11. Spaceworks Engineering, Inc., the company who completed the initial evaluation of torpor habitats for astronauts during long-term spaceflight, have recently been awarded $\$ 500,000$ from NASA to further their research and complete a Phase 2 study. This research will aid in the advancement and readiness of this technology.

In order to further identify and reduce the risks associated with torpor, testing can be completed prior to the mission both on Earth and on the ISS. Patients 
can be placed into torpor states in bed-rest studies in order to simulate the effects of micro-gravity and torpor on the body while being under constant observation on the ground. These tests will help identify and reduce any further risks not known. Isolation studies can also be completed with torpor. Four patients can be placed into isolation with one another while being placed in a torpor cycle. Isolation tests will help identify the benefits and psychological effects of rotating torpor cycles in an isolated environment. A torpor module can also be placed in an inflatable module on board the ISS to fully test the effects of multiple day torpor cycles in succession in a microgravity environment. All of these tests will further the readiness of the torpor technology and mitigate the risks associated with it.

Orion is equipped with a $\mathrm{CO}_{2}$ and Moisture Removal Amine Swing-bed (CAMRAS) atmospheric revitalization system. Orion is also equipped with an active thermal control flow system and trace contaminant system. A water recovery system will need to be integrated into the Orion capsule for the long-duration travel to and from Deimos. HARMONIA, modeled after Bigelow's BA-330 habitat, will accommodate the torpor pods for the crew. This inflatable environment will be equipped with the Sabatier carbon dioxide removal system, JPL E-Nose for fire detection, fine water mist fire extinguishers for fire suppression, a Vapor Phase Catalytic Ammonia Removal (VPCAR) system for water purification and recycling, and an Oxygen Generation Assembly (OGA) that is currently on the ISS. The trade study completed to determine the optimal $\mathrm{CO}_{2}$ removal system can be found in Table A.15 in Appendix A.

For launch, re-entry, and landing on both Earth and Deimos, crewmembers will use Modified Advanced Crew Escape Suits (MACES). The MACES suit provides a pressurized environment for the crew in the event of an emergency depressurization of the Orion capsule. This will allow the crew to initiate a launch-abort scenario during launch, or give enough time for the crew to move to HARMONIA if away from Earth. The MACES suit also functions as an emergency Extra-Vehicular Activity (EVA) suit. During EVA operations, the Z-series space suit will be used due to its advanced life support and mobility 
capabilities. The Z-series space suit will allow crew to complete all required work on the surface of Deimos. Additionally, the margins on consumables allow astronauts to perform emergency EVAs to perform spacecraft repairs while maintaining the nominal mission profile, despite having to depressurize and re415 pressurize Orion.

\section{Communications}

The communications system consists of two parabolic, high-gain antennas each with a diameter of $3 \mathrm{~m}$. In addition, four omni-directional antennas are installed to ensure constant telemetry, tracking, and command. These antennas are designed to work with X-band, the current standard of the Deep Space Network (DSN) and ESTRACK for interplanetary missions [19]. Moreover, the spacecraft will be equipped with a UHF communication system for teleoperation activities on Deimos and Mars and to allow for relay connections with nearby probes. This also enhances safety through redundancy and would allow for more

425 data to be sent to Earth. Figures 10 and 11 show that the downlink rate to Earth using the RF link is low during the astronauts stay at Deimos. Using the $34 \mathrm{~m}$ antennas, available in both the DNS and ESTRACK network, the downlink can drop to as low as $24 \mathrm{kbit} / \mathrm{s}$, assuming 100W transmitter power. This could be enhanced by using stronger transmitters such as the DSN 70 m antennas, K-band, or optical communications. The latter two are currently under development with promising results 20. Nonetheless, assuming the DNS network can be used at least as much as MRO is using it now [21], an average of 25 images per week, plus an estimated $1 \mathrm{kbit} / \mathrm{s}$ for astronaut monitoring, 1 $\mathrm{kbit} / \mathrm{s}$ for TTC, and $14 \mathrm{kbit} / \mathrm{s}$ for general communication can be allocated using ${ }_{435}$ QPSK modulation. These numbers can be adjusted and re-balanced according to demand for a given function. 


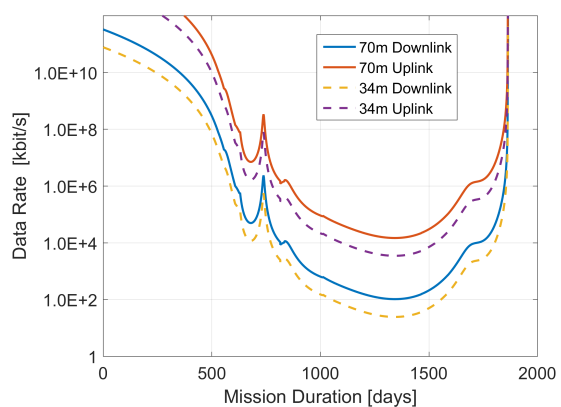

Figure 10: Data rate over the entire mission duration using $\mathrm{X}$-Band and a 100W spacecraft transmitter.

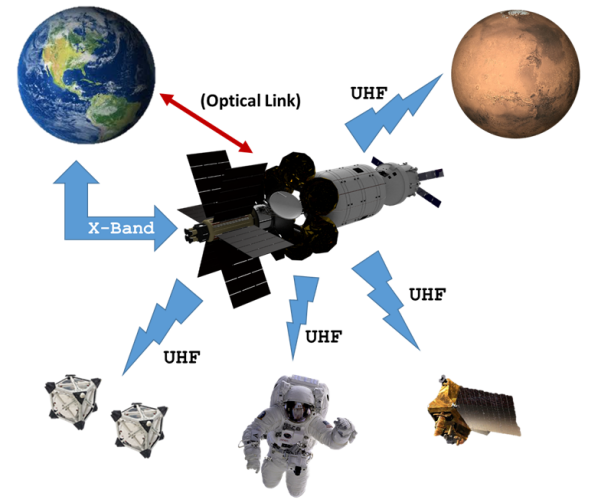

Figure 11: Communication pathways during the mission. An optical link would be desirable to increase data rates significantly.

\section{Science and Robotics}

The primary science and technology goals of the mission are to enable future crewed missions to the surface of Mars with interest in colonization. To achieve this, the mission deploys a network of science stations, demonstrates feasibility of fuel, water production, and 3D printing of large structures on the surface of Mars and its moons. Power will be provided to all ground assets from Space Solar Power (SSP) stations. Further science will be conducted by Moon Hoppers at the surface of Phobos, and by astronauts on Deimos. Human exploration is included in the mission to provide a subjective perspective of the inhabitability of the Martian system, ensure the most interesting aspects of the celestial bodies are being observed, and provide quality control in data collection. Pre-existing assets on the Martian ground that are still in working order, such as ExoMars, will be teleoperated from Deimos for technology demonstration. The mass of scientific payload is summarized in Table 5. To interact with robotics deployed at Deimos, the crew will utilize Shape Memory Alloy (SMA) beams. These are lightweight structures than can be easily extended and stored due to their thermal properties 22$]$.

Martian surface Analysis Network (MAN) 
Table 5: Mass summary for scientific equipment.

\begin{tabular}{lrrr}
\hline Equipment & Mass $[\mathrm{kg}]$ & Number & Total Mass $[\mathrm{kg}]$ \\
\hline Space Solar Power Station & 370 & 3 & 1110 \\
MAN stations & 71.5 & 54 & 3860 \\
Moon Hoppers & 60 & 2 & 120 \\
Moon Hoppers Propulsion Module & 244 & - & 244 \\
Deimos Science and ISRU Equipment & 800 & - & 800 \\
Mars Surface ISRU and Science Equipment & 2400 & - & 2400 \\
Sky Crane for Mars Surface Equipment & 750 & - & 750 \\
\hline Total & - & - & $\sim 9284$ \\
\hline
\end{tabular}

Three evenly spaced latitudinal profiles of 54 science stations will be landed between $0^{\circ}$ and $30^{\circ} \mathrm{N}$ (Figure 12 ).

Their locations will cover most of the area that meets landing requirements (both latitude and elevation) for future human missions. Each lightweight station $(36.5 \mathrm{~kg})$ is released in low Mars orbit and landed via airbags and retrorockets. One purpose of this network is to characterize Martian surface weather and soil properties at an unprecedented spatial and temporal resolution, to help identify optimal landing sites and enable the human exploration of Mars. Each station includes a seismometer, ground heat probe, temperature, wind (velocity and direction), and humidity sensors, a 360-degree panoramic camera, radiation sensor, a microscopic imager to determine regolith grain size, and a soil and organics test instrument to assess the nutrient and organics content of local regolith. Finally, each station will have a data transmission antenna and a microwave receiver for receiving power from orbit. Entry, Descent, and Landing (EDL) and structural mass is based on the Beagle 2 lander mass budget [23], which yields a revised total mass of $71.5 \mathrm{~kg} /$ station as shown in Table 6 .

A detailed mass breakdown can be found in Appendix D. To reduce cost and development time, the MAN stations use many heritage components. The cameras are inherited from the Mastcam on MSL and the heat probe from 
Figure 12: Example grid for the Martian surface Analysis Network, designed to characterize possible future landing sites for a manned mission to Mars.

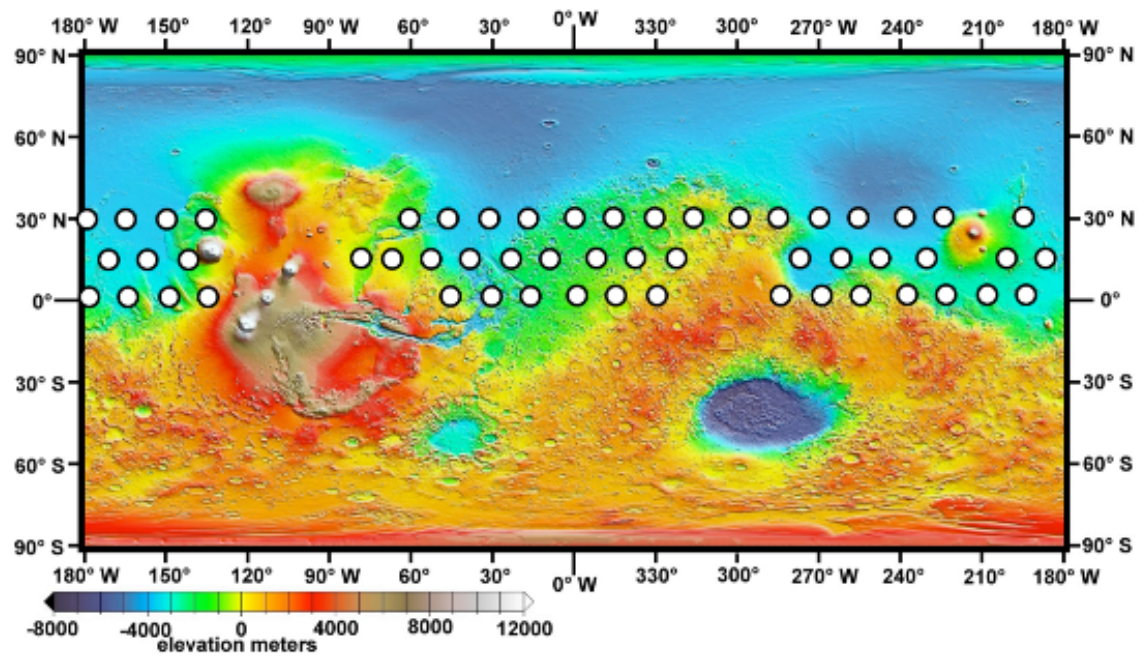

Table 6: MAN Station Mass Estimate.

\begin{tabular}{lr} 
Subsystem & Mass $[\mathrm{kg}]$ \\
\hline Probe & 35 \\
Lander & 24 \\
Science Payload & 12.5 \\
\hline Total & $\sim 71.5$ \\
\hline
\end{tabular}

INSIGHT. The organics detector is reused from the Sample Anaysis at Mars 475 (SAM) instrument suite on MSL.

Landers were favored over orbiters because the latter are unable to directly measure many of the ground surface properties the mission seeks to characterize, such as radiation levels, geothermal gradients, nutrients, perchlorate, volatiles, and dust contents of the soil. For the same mass, landers also provide data from 54 locations, as opposed to less than half a dozen if Curiosity-like rovers are used. More details can be found in the trade study shown in Table A.14 Cameras will allow imaging of assets of the ground (e.g. rock sizes/thermal 
inertia, relevant to building/shielding) that are below HiRISE resolution ${ }^{2}$. The MAN is critical for identifying optimal landing sites, allowing full coverage of the latitudinal region suitable for landing, and thus, paving the way to human exploration. In contrast, landing e.g. three isolated rovers would require to preselect landing sites from a fraction of the assets that are measurable from orbit, and would limit the range of future opportunities.

\section{Moon Hoppers}

Low gravity results in low traction, making it impossible for traditional rovers to drive safely on these celestial bodies. Thus, the Highland Terrain Hoppers (Hopter), jumping robots driven by three independent actuators consisting of electric motors, gears, and springs will be used. These robots have a reversible main body and three firing legs that allow them to hop and avoid obstacles much larger than their own size. Moon hoppers are designed to recover from falls and impacts, which are common with this method of maneuvering [24, 25, 26]. When utilizing moon hoppers, science equipment will be designed and mounted in a way that protects it from harsh conditions. Two moon hoppers will be deployed on Phobos to characterize its chemical and mineral composition and structure, with one characterizing spectroscopically blue terrain and the other characterizing spectroscopically red terrain [27. In addition to ISRU capabilities, their payloads include an alpha particle X-ray spectrometer for chemistry, X-ray diffraction spectrometer for mineralogy, microscopic imager, spectral camera, and a georadar. The total mass of each moon hopper is $60 \mathrm{~kg}$.

\section{Space Solar Power (SSP) Stations}

Three Space Solar Power (SSP) stations (370 kg each) capable of generating $200 \mathrm{~kW}$ each will orbit Mars providing continuous power coverage to all assets on the ground. In development at Caltech, these ultralight structures [3] allow solar energy to be concentrated onto thin photo voltaic (PV) panels, then beamed

\footnotetext{
${ }^{2}$ High Resolution Imaging Science Experiment onboard MRO. HiRISE offers the highest resolution of the Martian surface to this date, with a pixel size of about $30 \mathrm{~cm}$ at best, and has a relatively small footprint due to its high resolution.
} 

account for the relatively small receiver antenna area of the MAN stations, the solar power stations will orbit at an altitude of $200 \mathrm{~km}$ above the Martian surface. As they pass above each MAN station power will be transmitted in a tightly focused beam at frequencies of 3-10 GHz to the MAN station receiver. decrease power transmission losses. Using foldable booms, each can be packaged into a $1.5 \mathrm{~m}$ high and $1 \mathrm{~m}$ diameter cylinder, and deploy to a $60 \mathrm{~m}$ x $60 \mathrm{~m}$ planar surface. The phased antenna approach ensures power is generated and converted to microwaves locally. Current calculations show specific input power feasible. These stations will also provide power for future missions, eliminating the need for nuclear reactors. They will also act as relays, sending data back to Earth.

\section{In Situ Resource Utilization (ISRU)}

525 A miniaturized JPL ATHLETE robot 28] (450 kg) consisting of two fully independent three-limbed robots (Tri-ATHLETEs) will be used to move ISRU equipment around at a primary landing site on the Martian surface. The primary landing site will have autonomous fuel production units. These will take $50 \mathrm{~kg}$ of $\mathrm{H}_{2}$ feedstock and turn it into one metric ton of $\mathrm{CH}_{4}$ and $\mathrm{O}_{2}$. In addition to fuel production, the mission will bring $60 \mathrm{~kg}$ of raw materials and construction equipment such as scoops, levelers, and a large 3D printer. These materials and tools will allow for the assembly of large structures that will demonstrate the technology needed for habitats, the building of a storage dome to protect equipment from dust storms, and the 3D printer will aid in equipment construcOn Mars, the miniaturized ATHLETE will be able to carry up to $400 \mathrm{~kg}$ in payload. While not carrying any payload, the robots could be used to scout the area. Since the time delay is much smaller at Deimos than while operating from Earth, it can enable new activities never before done with rovers. On Deimos, 
found, these minerals will be crushed, baked and then liquid water extracted via a centrifuge. The water will be split into $\mathrm{H}_{2}$ and $\mathrm{O}_{2}$ and tested for its potential use in rocket fuel. The feasibility of utilizing processed regolith as heat shields for Martian landings will also be investigated.

\section{Teleoperation}

Astronauts on Deimos will be able to teleoperate rovers on Mars because of the minimal of a time delay. Teleoperation will enable Martian rovers that are still operable, such as the ExoMars rover, to be reused. This will allow for nearly real-time exploration of Mars and the examination of human-robotic interaction. Though existing rovers are slow, the lack of a time delay will make the operating process much faster. Traditional Mars rovers are designed to move slowly due to time delays, but since this mission aims to send humans near Mars, the new Tri-ATHLETE robots will be designed to move much faster, enabling astronauts to explore more of the Martian surface than ever before.

\section{Thermal Control System}

The main purpose of the Thermal Control System (TCS) is to cool the four SAFE-400 nuclear reactors which produce a thermal power of 3.84 MW. The core temperature of each reactor is $\sim 1200 \mathrm{~K}$ and it is assumed that the incoming coolant temperature shall not exceed a temperature of $\sim 500 \mathrm{~K}$. This results in a maximum radiator temperature of $\sim 700 \mathrm{~K}$. On this basis, the effective radiator area can be calculated to an area of $288 \mathrm{~m}^{2}$. Assuming a standard radiator geometry of 6 radiator panels, this results in $4 \mathrm{~m}$ by $6 \mathrm{~m}$ radiators. This gives a reasonable radiation geometry and mass estimates for such a large amount of power. This is possible due to the fact that a relatively high radiator temperature is used.

\section{Radiation Shielding}

On the surface of the Earth, humans are shielded by the majority of outer space radiations thanks to Earth's magnetic field and atmosphere. On the other 
hand, in space there are ionizing radiation and solar energetic particles. The

\section{Cost}

Initial cost estimates are based on mass, heritage, and the NASA AMCM including a $2 \%$ inflation rate. The operations costs are estimated from the ISS 
program [31. The total cost given in Table 7 is for the entire 20-year program, including development and a total of $\mathrm{B} \$ 10.4$ FY2016 in operations cost over eight years.

Table 7: Cost Budget.

\begin{tabular}{lr}
\hline & Cost [M\$] \\
\hline Phase A Wrap Cost & 28 \\
Phase B Wrap Cost & 331 \\
Phase C/D Wrap Cost & 2,253 \\
Development Cost $+20 \%$ & 5,712 \\
Spacecraft $+20 \%$ & 3,755 \\
Launcher Cost $+20 \%$ & 2,590 \\
Ground Control \& Operations 8 years & 10,400 \\
\hline Total & 24,974 \\
Total Inflation Corrected (FY2016) & 31,734 \\
\hline
\end{tabular}

After an inflation adjusted analysis of NASA's budget in accordance with the given ground rules (see Appendix B), this mission should have access to a total of approximately $\mathrm{B} \$ 102$ FY2016, with more than B $\$ 9$ FY2016 per year starting in 2026. Currently, the mission would use $31 \%$ of the total NASA yearly budget (assuming B $\$ 16$ FY2016 per year ), thus there is a large margin to absorb additional costs. Development costs are estimated using guidelines provided by the NASA Advanced Mission Cost Model (AMCM), and heritage 32]. Additionally, information available from press releases with regard to existing programs were considered for comparison and baselining. The resulting amounts are shown in Table 8 including a $65 \%$ margin for wrap costs.

A short reasoning and information on which sources were used are also provided. The total yearly mission cost is shown in Figure 13 . 
Table 8: Development of critical technologies. M\$ in FY2016.

\begin{tabular}{|c|c|c|}
\hline Technology & Cost $[\mathrm{M} \$]$ & Source of Estimate \\
\hline ECLSS - Torpor & 234 & $\begin{array}{l}\text { Based on NASA funding }+ \\
1 \text { launch }+3.6 \text {-year test en- } \\
\text { vironment }\end{array}$ \\
\hline $\begin{array}{l}\text { Science - Space Solar } \\
\text { Power }\end{array}$ & 876 & $\begin{array}{l}\text { Northrop Grumman fund- } \\
\text { ing budget and AMCM }+1 \\
\text { launch }\end{array}$ \\
\hline Science - MAN Station & 25 & $\begin{array}{l}\text { Development cost equal to } \\
\text { three units built }\end{array}$ \\
\hline Science - Moon Hopper & 57 & $\begin{array}{l}\text { Development cost equal to } \\
\text { building demonstrator }\end{array}$ \\
\hline $\begin{array}{l}\text { Deimos Science and } \\
\text { ISRU }\end{array}$ & 405 & $\mathrm{AMCM}+1$ launch \\
\hline Mars Science and ISRU & 394 & $\mathrm{AMCM}+1$ launch \\
\hline Propulsion - VASIMR & 1,910 & $\begin{array}{l}\text { NASA funding budget and } \\
\mathrm{AMCM}+1 \text { launch }\end{array}$ \\
\hline $\begin{array}{l}\text { EPS - SAFE-400 Fis- } \\
\text { sion Reactor }\end{array}$ & 855 & AMCM + launch \\
\hline
\end{tabular}

\section{Conclusions}

The mission design presented in this paper was created with the objective of being a sustainable and evolvable mission that makes use of a series of innovative technologies. In fact, the mothership was designed with the intent of being a reusable spacecraft for exploring the moons of Mars, and allow humans to eventually arrive in low Martian orbit and then descend onto the red planet's surface. The mothership is nominally kept in a parking orbit near EML2, which favors the use of the spacecraft for missions taking place both in cis-lunar and deep space. Resupplies can be performed to replenish the spacecrafts consum- 


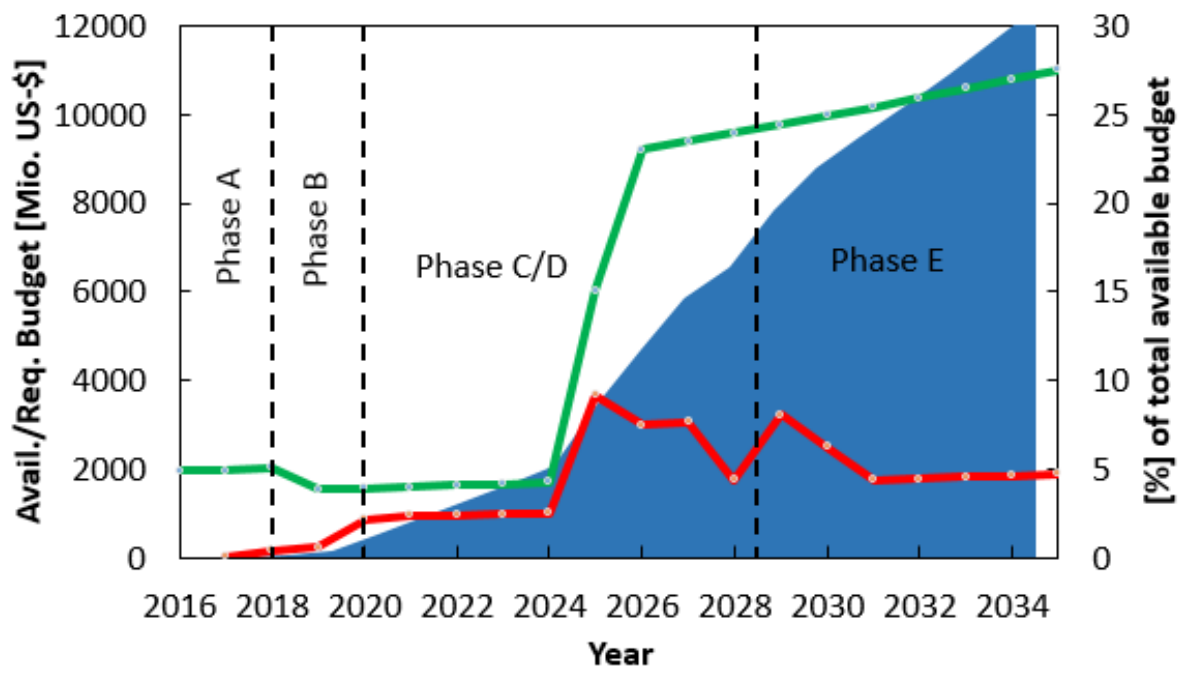

- Cumulative Cost/Total Avail. Budget - Avail. Budget - Req. Budget

Figure 13: The total mission cost (FY2016) per year is shown together with the available budget and the cumulative cost divided by the total available budget. Approximate time frames for the different mission phases are separated by vertical lines. Currently $31 \%$ of the total available budget from 2016-2035 is required.

ables and propellant for future missions in a similar way to how REVs are used. Another innovative trait of the mission presented in this paper is that the use of hybrid propulsion (chemical and electrical), combined with the trajectory optimization technique described in Appendix E which allows the IMaGInE mission to take place with the use of a relatively lightweight spacecraft.

This mission is aimed at enabling future exploration of Mars. In fact, the assets delivered to the Martian moons, such as the moon hoppers, and onto the Martian surface, such as the MAN stations and 3D printing equipment, are designed with the idea of being used for future missions in cis-martian space, not simply for a one-time use. Future missions will thus further our knowledge of Mars, Phobos, and Deimos and they will favor the establishment of human colonies on the red planet. 
635

The Innovative Mars Global International Exploration (IMaGInE) Mission is the resulting work of 15 students gathered from 11 universities and 8 different nations in 6 time zones. The objective was to create a mission design for the Crewed Mars Moons Mission theme proposed by the 2016 Revolutionsponsored by NIA and NASA. The mission ground rules established by the RASC-AL evaluating and judging committee are listed in Table B.16. In June 2016, the IMaGInE Mission was presented at the 2016 RASC-AL Forum in Cocoa Beach, FL and it was awarded with the "Best in Theme", "Best Overall" 645 and "Pioneering Exceptional Achievement Concept Honor (PEACH)" prizes. The student names are listed as authors starting with the team leader (Davide Conte) and then listed alphabetically for the remaining 14 students.

The team would like to thank the organizers of the RASC-AL competition, NIA, and NASA for their continuous help as well as their financial support which has allowed the team to present this project at the 2016 RASC-AL Forum in Cocoa Beach, FL in June 2016 and during AIAA SPACE 2016 in Long Beach, CA in September 2016. The team would also like to thank the Penn State committee of professors and experts that helped the team through a Preliminary 


\section{References}

[1] J. Bradford, M. Schaffer, D. Talk, Torpor inducing transfer habitat for human stasis to mars, Tech. rep., NASA Innovatic Advanced Concepts (NIAC) (2014).

[2] R. Shishko, R. Fradet, S. Saydam, S. Do, An Integrated Economics Model for ISRU in Support of a Mars Colony, 10th Symposium on Space Resource Utilization, 2017.

[3] M. Arya, N. Lee, S. Pellegrino, Ultralight structures for space solar power satellites, 3rd AIAA Spacecraft Structures Conference, 2016. doi: $10.2514 / 6.2016-1950$

q[4] Mission concept animation, https://drive.google.com/file/d/ OBwgBtxW3zpecUHgtalF3bGFNVTQ/view?usp=sharing.

[5] E. Bering, M. Giambusso, M. Carter, et al., Using VASIMR $\AA$ for the Proposed Europa Mission, AIAA SPACE 2014 Conference and Exposition, 2014. doi:10.2514/6.2014-4344.

[6] D. I. Poston, R. J. Kapernick, R. M. Guffee, Design and analysis of the SAFE-400 space fission reactor, in: Space Technology and Applications International Forum-STAIF 2002, Vol. 608, AIP Publishing, 2002, pp. 578588. doi:10.1063/1.1449775.

675 [7] Harvard-Smithsonian Center for Astrophysics, Chandra Telescope System, http://chandra.harvard.edu/about/telescope_system.html (Accessed: May 2016).

[8] W. J. Larson, L. Prankle, Human Spaceflight: Mission Analysis and Design, McGraw-Hill Companies, 1999.

${ }_{680}$ [9] NASA Risk Management Handbook, NASA/SP-2011-3422, Version 1.0, a http://www.hq.nasa.gov/office/codeq/doctree/NHBK_2011_3422. pdf (Accessed: May 2016). 
[10] Advancing Torpor Inducing Transfer Habitats for Human

1 Stasis to Mars, NASA, https://www.nasa.gov/feature/ advancing-torpor-inducing-transfer-habitats-for-human-stasis-to-mars

(Accessed: May 2016).

[11] Caltech - Division of Engineering and Applied Science, The Space Solar Power Initiative, http://eas.caltech.edu/engenious/twelve/idea_ flow (Accessed: May 2016).

[12] Ad Astra Rocket Company and NASA move to execution phase of n NextSTEP VASIMR partnership, http://spaceref.com/news/viewpr. html?pid=46574 (Accessed: May 2016).

[13] Ad Astra Rocket Company, First Flight Unit, http://www. adastrarocket.com/aarc/VF-200 (Accessed: May 2016).

695 [14] European Space Agency (ESA), Mars500 Human Spaceflight, http://www . esa.int/Our_Activities/Human_Spaceflight/Mars500 (Accessed: May 2016).

[15] G. Deckert, Risk Informed Design as Part of the Systems Engineera ing Process, http://ntrs.nasa.gov/archive/nasa/casi.ntrs.nasa. gov/20100037185.pdf, Presentation, CHSF Symposium AIAA NASA October 14-15, 2010.

[16] T. D. Smith, M. D. Klem, K. Fisher, Propulsion Risk Reduction Activities for Non-Toxic Cryogenic Propulsion, Space 2010 Conference and Exposition, 2010.

[17] Striepe, S. A. and Epp, C. D. and Robertson, E. A, Autonomous Precision landing and hazard avoidance technology (Alhat) project status as of May 2010, https://solarsystem.nasa.gov/docs/p457.pdf (2014).

[18] S. Ulamec, J. Biele, Surface elements and landing strategies for small bodies missions, Philae and beyond, Advances in Space Research 44 (3) (2009) 247-858. doi:10.1016/j.asr.2009.06.009. 
[19] JPL - Caltech, DSN Telecommunications Link Design Handbook, http: //deepspace.jpl.nasa.gov/dsndocs/810-005/ (Accessed: May 2016).

[20] NASA, Benefits of Optical Communications, http://www.nasa.gov/

1. directorates/heo/scan/engineering/technology/txt_opticalcomm_

715 benefits.html (Accessed: May 2016).

[21] JPL, Mars Reconnaissance Orbiter Telecommunications, http:// descanso.jpl.nasa.gov/DPSummary/MRO_092106.pdf/ (Accessed: May 2016).

[22] F. Schiedeck, Entwicklung eines Modells für Formgedächtnisaktoren im geregelten dynamischen Betrieb, PZH, Produktionstechn. Zentrum, 2009.

[23] D. Pullan, M. R. Sims, I. P. Wright, et al., Beagle 2: the exobiological lander of Mars express, in: Mars Express: The Scientific Payload, Vol. 1240, 2004, pp. 165-204.

[24] T. J. Steiner, S. A. Rasmussen, P. A. DeBitetto, et al., Unifying Inertial and Relative Solutions for Planetary Hopper Navigation, IEEE Aerospace Conference Proceedings, 2012. doi:10.1109/AERO.2012.6187307.

[25] B. E. Cohanim, A. N. Harrison, T. J. Mosher, et al., Small Lunar Exploration and Delivery System Concept, AIAA SPACE 2009 Conference and Exposition, 2009. doi:10.2514/6.2009-6712.

[26] P. M. Cunio, S. L. Nothnagel, E. Lanford, et al., Further Development and Flight Testing of a Prototype Lunar and Planetary Surface Exploration Hopper: Update on the TALARIS Project, AIAA SPACE 2010 Conference and Exposition, 2010.

[27] A. A. Fraeman, R. E. Arvidson, L. S. Murchie, et al., Analysis of diskresolved OMEGA and CRISM spectral observations of Phobos and Deimos,

【 Journal of Geophysical Research: Planets 117 (E11). doi:10.1029/ 2012JE004137. 
[28] M. Heverley, J. Matthews, , M. Frost, et al., Development of the tri-athlete lunar vehicle prototype, Proceedings of the 40th Aerospace Mechanisms Symposium, 2010.

[29] NASA, Types of Radiation in Space, www.nasa.gov/sites/default/ files/np-2014-03-001-jsc-orion_radiation_handout.pdf (Accessed: May 2016).

[30] Bigelow Aerospace (Accessed: May 2016). URL http://bigelowaerospace.com/b330/

[31] NASA FY 2015 President's Budget Request Summary, https: 1] //www.nasa.gov/sites/default/files/files/508_2015_Budget_ Estimates.pdf (Accessed: May 2016).

[32] D. E. Koelle, Handbook of Cost Engineering and Design of Space Transportation Systems: With TransCost 8.2 Model Description; Statisticalanalytical Model for Cost Estimation and Economic Optimization of Launch Vehicles, Ottobrunn: TCS - TransCostSystems, 2013.

[33] J. B. Hopkins, W. D. Pratt, Comparison of Deimos and Phobos as destinations for human exploration and identification of preferred landing sites, AIAA SPACE 2011 Conference and Exposition, 2011.

[34] P. Dysli, Analytical ephemerides for planets, Dysli.

[35] J. A. Sims, S. N. Flanagan, Preliminary design of low-thrust interplanetary missions, AAS/AIAA Astrodynamics Specialist Conference, 2006, 2006.

[36] F. Zuiani, M. Vasile, Extended analytical formulas for the perturbed Keplerian motion under a constant control acceleration, Celestial Mechan-

1. ics and Dynamical Astronomy 121 (3) (2015) 275-300. doi:10.1007/ s10569-014-9600-5. 


\section{Appendix A: Trade-off Matrices}

This appendix provides the trade-off matrices that are the result and justifications of various trade studies for subsystems and general mission decisions.

Table A.9: Trade-off Phobos vs. Deimos for the crewed portion of the mission [33. 1- not important, 5 - important.

\begin{tabular}{|c|c|c|c|c|c|c|}
\hline & \multicolumn{3}{|l|}{ Phobos } & \multicolumn{3}{|l|}{ Deimos } \\
\hline & Rationale & Pro & Con & Rationale & Pro & Con \\
\hline & $\begin{array}{l}\text { Double the gravity, easier for sur- } \\
\text { face operations and ISRU }\end{array}$ & 3 & & $\begin{array}{l}\text { Very subdued surface, likely } \\
\text { mantled in regolith, not much ac- } \\
\text { cess to bedrock }\end{array}$ & & 3 \\
\hline & $\begin{array}{l}\text { Thick regolith }(200 \mathrm{~m}) \text {, might be } \\
\text { harder to get to bedrock }\end{array}$ & & 2 & $\begin{array}{l}\text { Hemispheric-size crater, may } \\
\text { provide access to the subsurface }\end{array}$ & 5 & \\
\hline & $\begin{array}{l}\text { Might be plastered with Mars } \\
\text { material }\end{array}$ & 2 & & $\begin{array}{l}\text { Less probability of finding Mars } \\
\text { material }\end{array}$ & & 3 \\
\hline & More likely to be differentiated & 3 & & Less likely to be differentiated & & 3 \\
\hline & $\begin{array}{l}\text { Large impacts (Stickney crater) } \\
\text { and pits provide access to the } \\
\text { subsurface }\end{array}$ & 5 & & $\begin{array}{l}\text { From Viking encounter seems to } \\
\text { be smooth at } 1 \mathrm{~m} \text { scale, i.e. less } \\
\text { risky to land on a large rock }\end{array}$ & 3 & \\
\hline & $\begin{array}{l}\text { Less frequent line of communica- } \\
\text { tion to Earth }\end{array}$ & & 2 & $\begin{array}{l}\text { More frequent direct line of com- } \\
\text { munication to Earth because, as } \\
\text { viewed from Deimos, Mars does } \\
\text { not occult Earth as frequently }\end{array}$ & 2 & \\
\hline & $\begin{array}{l}\text { Orbital period is } 8 \text { hours, more } \\
\text { direct line of sight to Mars }\end{array}$ & 5 & & $\begin{array}{l}\text { Orbital period is } 30 \text { hours, limit- } \\
\text { ing the amount of visibility with } \\
\text { the Martian surface per sol }\end{array}$ & & 4 \\
\hline & $\begin{array}{l}\text { Needs a } \Delta V \text { of } 1570 \mathrm{~m} / \mathrm{s} \text { more } \\
\text { than to get only to Deimos (same } \\
\text { amount of the final Trans-Mars- } \\
\text { Injection) }\end{array}$ & & 5 & $\begin{array}{l}\text { No need for additional } \Delta V \text { of } \\
1570 \mathrm{~m} / \mathrm{s}\end{array}$ & 5 & \\
\hline & $\begin{array}{l}\text { Assets can be teleoperated on } \\
\text { Mars up to } 64.8 \text { deg latitude }\end{array}$ & & 3 & $\begin{array}{l}\text { Assets can be teleoperated on } \\
\text { Mars up to } 80.2 \text { deg latitude }\end{array}$ & 3 & \\
\hline & $\begin{array}{l}\text { Short communication passes to } \\
\text { sites on Mars ( } 4 \text { hours) }\end{array}$ & & 3 & $\begin{array}{l}\text { Longer communication passes to } \\
\text { sites on Mars ( } 2.5 \text { days) }\end{array}$ & 3 & \\
\hline & $\begin{array}{l}\text { Radiation: Mars fills } 3.4 \% \text { of the } \\
4 \pi \text { steradian sky }\end{array}$ & 2 & & $\begin{array}{l}\text { Radiation: Mars fills } 0.5 \% \text { of the } \\
4 \pi \text { steradian sky }\end{array}$ & & 2 \\
\hline & $\begin{array}{l}\text { Worse illumination conditions } \\
\text { than Deimos }\end{array}$ & & 3 & $\begin{array}{l}\text { Better illumination conditions } \\
\text { than Phobos }\end{array}$ & 3 & \\
\hline TOT. & & 20 & 18 & & 24 & 15 \\
\hline Pro/Con & & & & & & \\
\hline
\end{tabular}


Table A.10: Trade-off for propulsion technologies. ${ }^{*}$ related to the respective $I_{s p} ;{ }^{* *}$ related to the respective thrust.

\begin{tabular}{lllllll}
\hline $\begin{array}{l}\text { Propulsion } \\
\text { technology }\end{array}$ & $\begin{array}{l}\text { resulting } \\
\text { payload fraction* }\end{array}$ & $\begin{array}{l}\text { IMLEO } \\
\text { mass* }\end{array}$ & $\begin{array}{l}\text { resulting } \\
\text { Time of Flight** }\end{array}$ & TRL & Safety & $\begin{array}{l}\text { Final } \\
\text { ranking }\end{array}$ \\
\hline Chemical & -- & -- & + & ++ & ++ & 2. \\
Nuclear thermal & - & - & + & -- & -- & 3. \\
Electrical & ++ & ++ & - & + & ++ & 1. \\
\hline
\end{tabular}

Table A.11: Trade-off for EPS technologies

\begin{tabular}{|c|c|c|c|c|c|c|c|}
\hline $\begin{array}{l}\text { EPS } \\
\text { technology }\end{array}$ & $\begin{array}{l}\text { Max power } \\
\text { generation }\end{array}$ & $\begin{array}{l}\text { Influence of } \\
\text { Sun distance }\end{array}$ & $\begin{array}{l}\text { Weight } \\
\text { specific power }\end{array}$ & TRL & $\begin{array}{l}\text { Expand- } \\
\text { ability }\end{array}$ & Safety & $\begin{array}{l}\text { Final } \\
\text { ranking }\end{array}$ \\
\hline Solar & + & - & + & ++ & 0 & ++ & 2. \\
\hline Nuclear & ++ & ++ & ++ & 0 & ++ & 0 & 1. \\
\hline Stored & - & ++ & -- & - - & -- & - & 3. \\
\hline
\end{tabular}

Table A.12: Trade-off soft vs. hard landing on Deimos

\begin{tabular}{llllll}
\hline $\begin{array}{l}\text { Type of } \\
\text { landing }\end{array}$ & Bounce risk & $\begin{array}{l}\text { Damping } \\
\text { energy stored }\end{array}$ & $\begin{array}{l}\text { Fuel } \\
\text { consumption }\end{array}$ & Contamination & $\begin{array}{l}\text { Final } \\
\text { ranking }\end{array}$ \\
\hline Soft & -- & + & -- & - & 1. \\
Hard & --- & ++ & - & --- & 2. \\
\hline
\end{tabular}

Table A.13: AOCS thruster selection

\begin{tabular}{llllll}
\multicolumn{7}{c}{ Table A.13: AOCS thruster selection } \\
\hline Type of Thruster & Performance & Toxicity & Storing & Refueling & Final \\
\hline Hydrazine & +++ & -- & + & - & 2. \\
Green Biowaste (Oxygen/methane) & ++ & ++ & ++ & ++ & 1. \\
\hline
\end{tabular}

Table A.14: Trade-off on type of science surface assets

\begin{tabular}{llllll}
\hline & & & 3 & Soil/Radiation & Final \\
& Mass & Redundancy & Measurement & Surface Area Covered & \begin{tabular}{l} 
ranking \\
\hline Single Orbiter
\end{tabular} \\
++ & - & - & ++ & 2. \\
Rovers x3 & + & - & ++ & -- & 3. \\
Landers x54 & + & ++ & ++ & ++ & 1. \\
\hline
\end{tabular}


Table A.15: $\mathrm{CO}_{2}$ Removal Trade Study.

\begin{tabular}{|c|c|c|c|}
\hline & Sabatier & Bosch & $\mathrm{LiOH}$ \\
\hline Inputs & $\begin{array}{l}\mathrm{CO}_{2}, \mathrm{H}_{2}, \quad\left[\mathrm{H}_{2} / \mathrm{CO}_{2}\right. \\
=4.5], \text { Heat }\end{array}$ & $\mathrm{CO}_{2}, \mathrm{H}_{2}$, heat & $\begin{array}{l}\mathrm{H}_{2} \mathrm{O}, \mathrm{CO}_{2}, \mathrm{~N}_{2}, \mathrm{O}_{2}, \\
\mathrm{LiOH}\end{array}$ \\
\hline Outputs & $\mathrm{CH}_{4}$, heat, $\mathrm{H}_{2} \mathrm{O}$ & $\mathrm{C}, \mathrm{H}_{2} \mathrm{O}$, heat & $\begin{array}{l}\mathrm{H}_{2} \mathrm{O}, \mathrm{N}_{2}, \mathrm{O}_{2}, \mathrm{CO}_{2}, \\
\mathrm{H}_{2} \mathrm{O}\end{array}$ \\
\hline Efficiency & $96 \%$ & $\mathrm{~N} / \mathrm{A}$ & $\mathrm{N} / \mathrm{A}$ \\
\hline TRL & 6 & 4 & 8 \\
\hline Operability & $\begin{array}{l}\text { yAutonomous. Only } \\
\text { maintenance re- } \\
\text { quired involves part } \\
\text { replacements after } \\
\text { long durations of } \\
\text { mechanical wear. }\end{array}$ & $\begin{array}{l}\text { Integration more } \\
\text { complex than } \\
\text { Sabatier. Catalyst } \\
\text { cartridge must be } \\
\text { periodically replaced } \\
\text { by crew members. }\end{array}$ & $\begin{array}{l}\text { Non-regenerable. } \\
\text { The reaction that } \\
\text { occurs from the } \\
\mathrm{LiOH} \text { sorbent is ir- } \\
\text { reversible. The crew } \\
\text { will need to replace } \\
\mathrm{LiOH} \text { cartridges } \\
\text { daily making this a } \\
\text { poor interface for } \\
\text { the crew. }\end{array}$ \\
\hline
\end{tabular}




\section{Appendix B: Ground Rules and Top Level Requirements}

\section{Mission Statement:}

The IMaGInE Mission (Innovative Mars Global International Exploration Mission) will deliver a crew of four astronauts to the surface of Deimos for 300 days during the years 2028 and 2034. The crew will perform surface excursions, technology demonstrations, and ISRU of the Martian Moon as well as site reconnaissance for future human exploration of Mars.

Table B.16: Ground Rules given by the RASC-AL 2016 judging committee

GR.1 Mission must take place between 1/1/2015 and 12/31/2035

GR.2 Yearly NASA budget is B $\$ 16$ (adjusting for inflation only)

GR.3 Must have a crew of four

GR.4 Must arrive at the surface of Phobos and/or Deimos

GR.5 Must stay on the surface of Phobos and/or Deimos for at least 300 days

GR.6 Must perform Mars moons surface exploration, technology demonstration, ISRU

GR.7 Must perform reconnaissance on Mars to facilitate future Mars human missions

GR.8 Must include tele-operated experiments on the surface of Mars

GR.9 Maintain at least $80 \%$ of NASA's total budget for existing NASA programs

GR.10 ISS will be fully funded until 2024

GR.11 SLS and Orion will be developed and operational through 2025 at their current budgets 
TL.1 Conduct a human mission to the moons of Mars be- GR.1 tween $1 / 1 / 2015$ and $12 / 31 / 2035$

TL.2 Deliver and return four human crew members to

GR.3, /from the moons of Mars safely

GR. 4

TL.3 Do not exceed a yearly NASA budget of B $\$ 16$ ad- GR.2, justed for inflation and GR.9,

- Maintain at least $80 \%$ of NASA's total budget for GR.10, existing NASA programs

GR.11

- ISS will be fully funded to 2024

- SLS and Orion will be developed and operational through 2025 at their current budgets

TL.4 Four crewmembers have to survive on moon surface and be able to conduct EVAs for at least 300 days

GR.5,

TL.5 Perform Mars moon surface exploration GR.6

GR.6

TL.6 Perform technology demonstration GR.6

TL.7 Perform ISRU GR.6

$\begin{array}{lll}\text { TL.8 } & \text { Perform Mars reconnaissance } & \text { GR.7 }\end{array}$

TL.9 Prepare future human missions to Mars $\quad$ GR.7

TL.10 Perform tele-operated experiments on the surface of GR.8 Mars

\section{Appendix C: Risk Analysis and Mitigation Strategies}

Risks related to all subsystems are rated according to the NASA risk management standard (NASA/SP-2011-3422) [9]. The resulting risk matrix is shown in Figure C.18. Mitigation strategies are implemented according to the severity of the risk and it is possible to reduce the majority of critical risks to a Loss of Mission (LOM) in the worst case, except for a failure of the crewed launch vehicle. The labels in the risk matrix refer to the numbering given to various 
risks and their respective mitigation strategies as listed below. Note that an inherent risk not shown in the matrix, but probably causing the mission to undergo major changes and cost increases is scheduling. This is due to a number of technologies that have to be developed from low TRL to at least TRL 6 or 7 , and the required testing of critical technologies and launchers has to be con785 sidered. All of these developments need to be assessed critically and a rigorous timeline management needs to be implemented. Below is a list of the main mission risks along with their associated mitigation strategies. Their enumeration number corresponds to the number shown in the risk matrix (Figure C.18)

Table C.18: Risk matrix. Green, yellow and red stand for low, medium and high probability/consequence respectively. Rows = consequence; columns = probability.

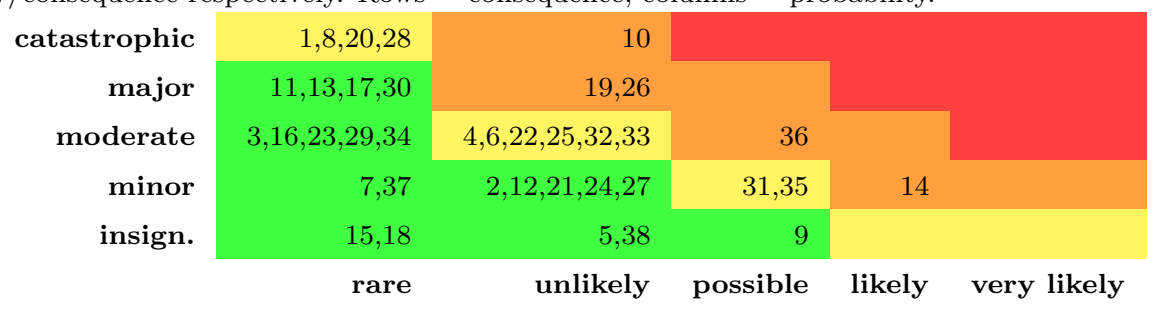

\section{Trajectories}

1. Science Payload: TMI maneuver is not fully successful. If the necessary $\Delta \mathrm{V}$ to obtain the prescribed $\mathrm{V}_{\infty}$ cannot be achieved, this may result in a LOM for the scientific equipment. Another launch may be attempted resulting in a higher launch cost.

2. The lunar flyby maneuver during the inbound trajectory of the test crew vehicle is not timed correctly or fails. If Orion's propulsion system is still working, a maneuver can be performed after the failed propulsive lunar flyby to return safely to Earth; TOF is estimated to be 6-10 days.

3. A subsystem such as ECLSS has a partial failure right after TLI and the test mission/main mission crew is required to be back at Earth as soon as possible. Mitigation A: if failure occurs within the first 3-4 days of TLI, a $\Delta \mathrm{V}$ can be performed to change the outbound trajectory to a 
free-return trajectory. Estimated TOF from TLI to Earth reentry: 10-11 days. Mitigation B: if a failure occurs after 3-4 days from TLI, a $\Delta V$ can be performed at the lunar flyby to return to Earth safely without exceeding Orion's reentry velocity capability.

4. Failed orbit insertion at EML2. A propulsive maneuver can be performed at a later time than the nominal EML2 insertion in order to arrive at a different halo orbit and then perform a rendezvous maneuver with HERMES+HARMONIA. If no alternative halo orbit can be achieved, perform a flyby of the Moon again and return safely back to Earth; TOF is estimated to be in the order of 8-13 days.

5. Maneuver to return to Earth at the end of the mission fails. A propulsive maneuver can be performed at a later time. This results in a small correction in order to return to Earth safely within 10 days and at nominal reentry velocity of $11 \mathrm{~km} / \mathrm{s}$.

\section{Communications}

6. Main communications system fails. Backup communication systems is used. Data rate may be lower.

7. Line of sight with Earth is obscured and communication with Earth is lost. Crew must wait until line of sight with Earth is reestablished.

\section{Launch Vehicles}

8. Falcon Heavy carrying the science mission malfunctions/fails to deliver the payload into orbit. Enough buffer time is given between the science pre-deployment and the crewed mission so that another launch can be attempted. Results in higher cost and delay of science schedule.

9. Poor weather conditions do not allow the launch to occur on the nominal date. Reschedule the launch to a different date within the launch window.

10. SLS payload capacity is reduced. Perform the launch of HERMES and HARMONIA using two launches. Increased launch cost and may cause slight delay in launch schedule. 
11. Falcon Heavy payload capacity is reduced. Margins ensure that the science mission may still be able to be launched using one Falcon Heavy. Otherwise, use 2 Falcon Heavy launches or decrease the amount of science equipment to be delivered at the Martian system.

\section{Electrical Power System (EPS)}

12. One SAFE-400 reactor fails. Less power can be delivered to the VASIMR engines, reducing thrust and increasing TOF. Stay time at Deimos may be shortened.

13. Two or more SAFE-400 reactors fail. LOM. Abort trajectory is implemented using the remaining power if possible. Otherwise, LOC.

\section{Thermal Control System (TCS)}

14. Unexpected eclipse from the Sun. Include at least one layer of MLI to ensure thermal inertia. Include heating device.

15. Coating absorptivity or emissivity degrades due to unexpected high solar radiation and/or galactic cosmic rays. Heating device and auxiliary radiator are utilized.

16. Heater/Radiator fails. If all radiators were to fail, crew may have to execute a premature Earth return.

17. Complete or partial system failure. It affects mainly EPS, causing a decreased power output and thus less thrust. Abort trajectory is implemented if necessary using the remaining power if possible. If failure is only minimal, stay time at Deimos may be decreased with no need for abort.

\section{Environmental Control and Life Support System (ECLSS)}

18. IVA suit failure. Use backup IVA suit.

19. EVA suit failure. EVA abort. Repair failure, use backup EVA suit, or use IVA suit in emergency case.

20. Cabin depressurization of either habitable vehicle. Launch: Abort mission (LOM), IVA suits will be donned and automatically pressurize and 
ensure crew safety until return to Earth. Transit: Enter other habitable vehicle and don IVA suits. Assess repairability and mission viability (may cause LOM). Reentry: Continue descent, IVA suits will be donned and automatically pressurize and ensure crew safety until return to Earth.

21. Torpor module failure. Awaken associated crewmember. Use spares to repair torpor module.

22. Sickness/injury of crewmember due to microgravity or torpor. Monitor crew health, follow mitigation techniques of known torpor risks, and follow proper workout protocol to reduce microgravity risks.

Further details concerning risk and mitigation strategies solely related to torpor can be found in Table C.19.

\section{Attitude and Orbit Control System (AOCS) and Landing/Ascent}

23. AOCS thrusters underperform. Margins in propellant mass are taken into account to ensure the spacecraft has enough propellant should the AOCS thrusters underperform.

24. One or more AOCS thrusters malfunction and/or fail. Redundant/backup AOCS thrusters are used.

25. Landing gear does not function properly at landing or ascent. AOCS thrusters can be used as backup. May lower the science astronauts can perform at Deimos due to not being in direct contact with the surface of Deimos.

26. Docking with the resupply vehicle at Deimos fails. If no critical subsystems are damaged and enough $\Delta \mathrm{V}$ is available, retry the docking maneuver; this may result in a reduced time for scientific exploration at Deimos. If docking with the resupply vehicle is impossible, the stay time at Deimos must be shortened to 100 days. Partial LOM.

\section{Propulsion}

27. One VASIMR engine fails. TOF is extended and stay time at Deimos is shortened. Two or more VASIMR engines fail. LOM. Abort trajectory is implemented using the remaining engines if possible. Otherwise, LOC. 
28. Fuel leakage caused by micrometeorite impacts. Crew may be able to repair the damage by going outside using EVA suits. If the damage cannot be repaired, mission is aborted causing LOM. 
Table C.19: Torpor Health Risks and Mitigation Strategies. 1]

\begin{tabular}{|c|c|c|}
\hline Risk & Initiator & $\begin{array}{l}\text { Mitigation Technique / Com- } \\
\text { ments }\end{array}$ \\
\hline Blood Clotting & $\begin{array}{l}\text { Prolonged sleep and } \\
\text { indwelling IVs }\end{array}$ & $\begin{array}{l}\text { Minimize IV access, and perform } \\
\text { periodic heparin flushed to dissolve } \\
\text { clots }\end{array}$ \\
\hline Bleeding & $\begin{array}{l}\text { Decrease in coagu- } \\
\text { lation factor activ- } \\
\text { ity }\end{array}$ & $\begin{array}{l}\text { Not a significant concern outside of } \\
\text { trauma }\end{array}$ \\
\hline Infection & $\begin{array}{l}\text { Temperature reduc- } \\
\text { tion in white blood } \\
\text { cell activity }\end{array}$ & $\begin{array}{l}\text { Minimize IV access, practice sterile } \\
\text { techniques, and use of tunneled } \\
\text { catheters and antibiotic-infused } \\
\text { catheters }\end{array}$ \\
\hline $\begin{array}{l}\text { Electrolyte and } \\
\text { Glucose Imbal- } \\
\text { ances }\end{array}$ & $\begin{array}{l}\text { Decreased cellular } \\
\text { metabolism }\end{array}$ & $\begin{array}{l}\text { Close monitoring of crew health and } \\
\text { IV stabilization }\end{array}$ \\
\hline $\begin{array}{l}\text { Fatty Liver and } \\
\text { Liver Failure }\end{array}$ & $\begin{array}{l}\text { Long term torpor } \\
\text { usage }\end{array}$ & $\begin{array}{l}\text { Alternate source of lipids used, and } \\
\text { proper diet and exercise when not } \\
\text { in torpor }\end{array}$ \\
\hline $\begin{array}{l}\text { Other Compli- } \\
\text { cations }\end{array}$ & $\begin{array}{l}\text { Torpor usage and } \\
\text { reduced metabolic } \\
\text { rate }\end{array}$ & $\begin{array}{l}\text { Augment torpor system with in- } \\
\text { sulin, exogenous CCK, and other } \\
\text { risk-preventing hormones, and fol- } \\
\text { low proper protocol for inducing } \\
\text { and awaking from torpor }\end{array}$ \\
\hline
\end{tabular}




\section{Radiation Shielding}

30. No adequate shielding material is developed/researched for the main mission timeframe. May cause delays and/or partial LOM due to time constraints in interplanetary space.

31. Underestimated length of radiation event. Astronaut schedule may be changed to accommodate to the unexpected/underestimated radiation event.

\section{Robotics}

32. Moon hoppers get stuck in the Martian moon's terrain. Astronauts can try to teleoperate the moon hoppers to free them.

33. Moon hoppers are covered in dust and do not receive enough solar energy from their solar arrays. Science return may be diminished.

34. Springs mounted on the moon hoppers used for mobility malfunction. Loss of moon hopper. Redundancy assures that another moon hopper would be available.

\section{Science}

35. One or more MAN stations malfunction. Network covered by the MAN stations is reduced. The high number of MAN stations deployed provides redundancy.

36. Space Solar Power Station does not deliver enough power to all the MAN stations. Some MAN stations may not be able to function continuously thus reducing the coverage of the MAN station network.

37. ISRU equipment does not function properly/malfunctions. ISRU experiments may not be conducted as intended. Lower science return. The crew is not affected.

38. Communication between astronauts and equipment on the Martian surface partially/completely malfunctions. Backup communication systems are used. 


\section{Appendix D: MAN Station Mass Breakdown}

Tables D.20 D.21, and D.22 provide a detailed summary of the mass breakdown for each portion of the MAN stations: scientific payload, lander, 925 and probe respectively.

Table D.20: Scientific Payload Mass Budget

\begin{tabular}{lr}
\hline Scientific Payload & Mass $[\mathrm{kg}]$ \\
\hline Seismometer and ground heat probe & 3 \\
Temperature, wind and humidity sensor & 2 \\
Radiation sensor & 0.5 \\
360 degree panoramic camera & 0.5 \\
Soil test instrument & 1 \\
Organics test instrument & 5 \\
Microscope imager to determine regolith grain size & 0.5 \\
\hline Subtotal & 12.5 \\
\hline
\end{tabular}

Table D.21: Lander Mass Budget

\begin{tabular}{lr}
\hline Lander & Mass [kg] \\
\hline Structure & 12 \\
Microwave receiver & 1 \\
Antenna for data transmission & 1 \\
Miscellaneous (battery, electronics, cabling, etc.) & 10 \\
\hline Subtotal & 24 \\
\hline
\end{tabular}


Table D.22: Probe Mass Budget

\begin{tabular}{lr}
\hline Probe & Mass [kg] \\
\hline Structure (heatshield and back cover) & 18 \\
Parachutes & 3 \\
Airbags \& gas generator & 14 \\
\hline Subtotal & 35 \\
\hline
\end{tabular}

\section{Appendix E: Low-Thrust Trajectory Optimization}

The optimal low-thrust interplanetary trajectory from the SOI of the Earth to the SOI of Mars has been computed considering the real ephemerides of Earth and Mars at given departure and arrival dates 34 .

Electric propulsion, while highly efficient, requires the engines to operate during a significant fraction of the trajectory and this makes it particularly difficult to find optimal trajectories 35 . The methods used to solve the lowthrust trajectory optimization problem generally fall into two categories: direct and indirect methods. Indirect methods are based on calculus of variations and on the formulation of a two-point boundary problem involving a set of costate variables, the solution of which yields a history of the time-dependent controls. Finding a solution using indirect method is often difficult because of several reasons: the size of the dynamical system doubles in size when adding the costate variables, the convergence domain tends to be small and the problem is sensitive to the initial guesses of the costate variables, which are generally not physically intuitive. Direct methods, on the other hand, are based on the parametrization of the controls and use nonlinear programming (NLP) techniques to optimize the performance index. Advantages of direct methods are the increased computational efficiency, more robust convergence and a reduced sensitivity to the initial guess, which is moreover physically more intuitive than for indirect methods. Different methods are available to solve direct optimization method, e.g., single shooting, multiple shooting, and collocation.

The optimal low-thrust trajectory for the transfer from Earth to Mars has 
been computed using a direct method and a multiple shooting algorithm. The trajectory is segmented into a sequence of coast and thrust legs. The objective of the non linear programming problem is to minimize the propellant consumption subjects to constraints (the initial state vector of the spacecraft has to coincide with the state vector of the Earth at departure, the final state vector has to coincide with the state vector of Mars at arrival, the initial and final points of the coast and thrust legs have to match). The non-linear programming problem has been solved using the Matlab ${ }^{\circledR}$ fmincon-interior point algorithm. The variables to optimize are the state vectors at the initial and final point of each thrust legs and the thrust direction over those legs.

The model used by the optimization method is an analytical propagator for the trajectory subject to the low-thrust acceleration [36]. This speeds up the computational process with respect to a numerical propagation, since in an optimization problem the trajectory has to be evaluated several time. 


\section{Appendix F: Resupply interplanetary trajectory}

The method used to compute the resupply interplanetary trajectory for the 965 Martian Moons Resupply and Science Deployment (MMRSD) is described in Appendix E. The obtained trajectory for this resupply and science deployment is shown in Figure F.14, with thrusting arcs shown in red and coasting arcs in green. The circles along the trajectory show points where the thrust angle direction is changed for the next thrust arc.

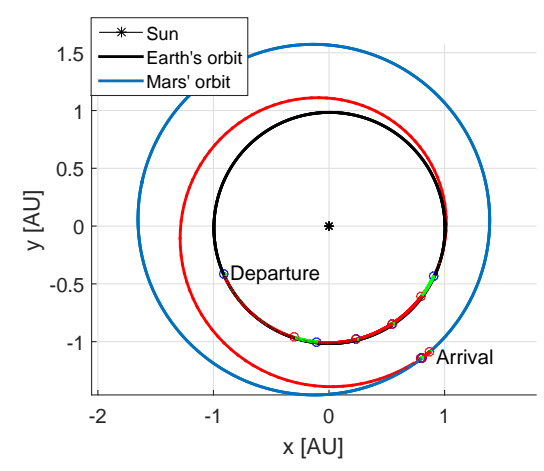

Figure F.14: Interplanetary trajectory from the SOI of Earth to the SOI of Mars for MMRSD 
Figure F.15 shows the diagram of the mothership + Orion from different perspectives while Figure F.16 shows the mission logo depicting Mars and Deimos in the background, the crewed spacecraft on the left, and the faces of the authors of this mission concept on the right.

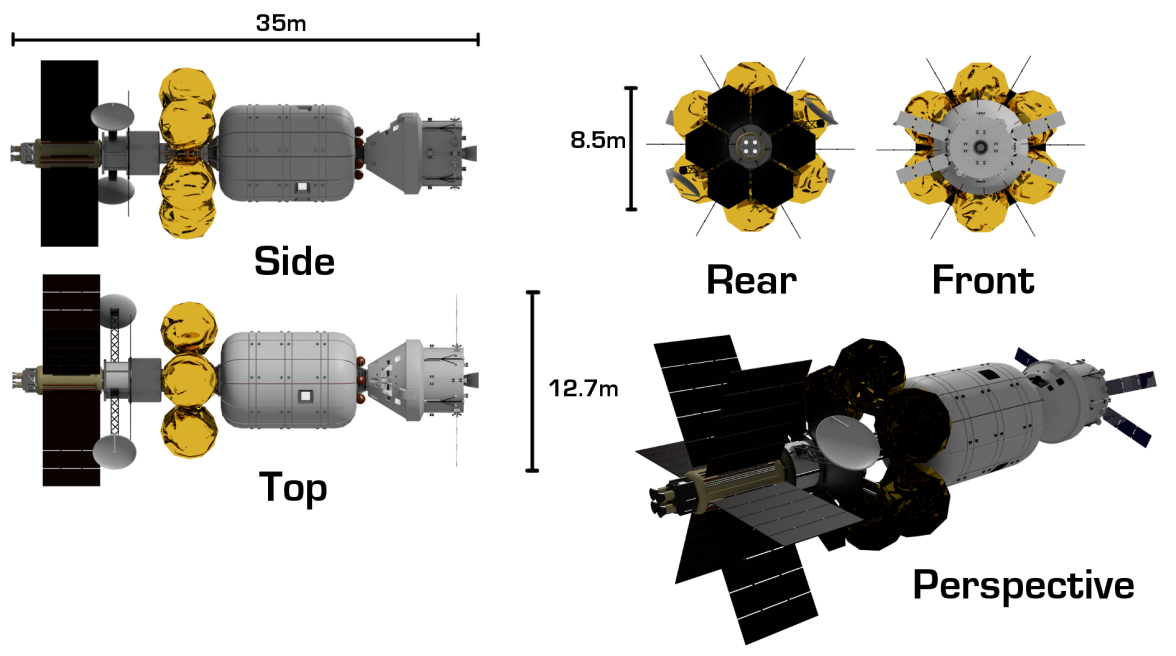

Figure F.15: Mothership diagram 


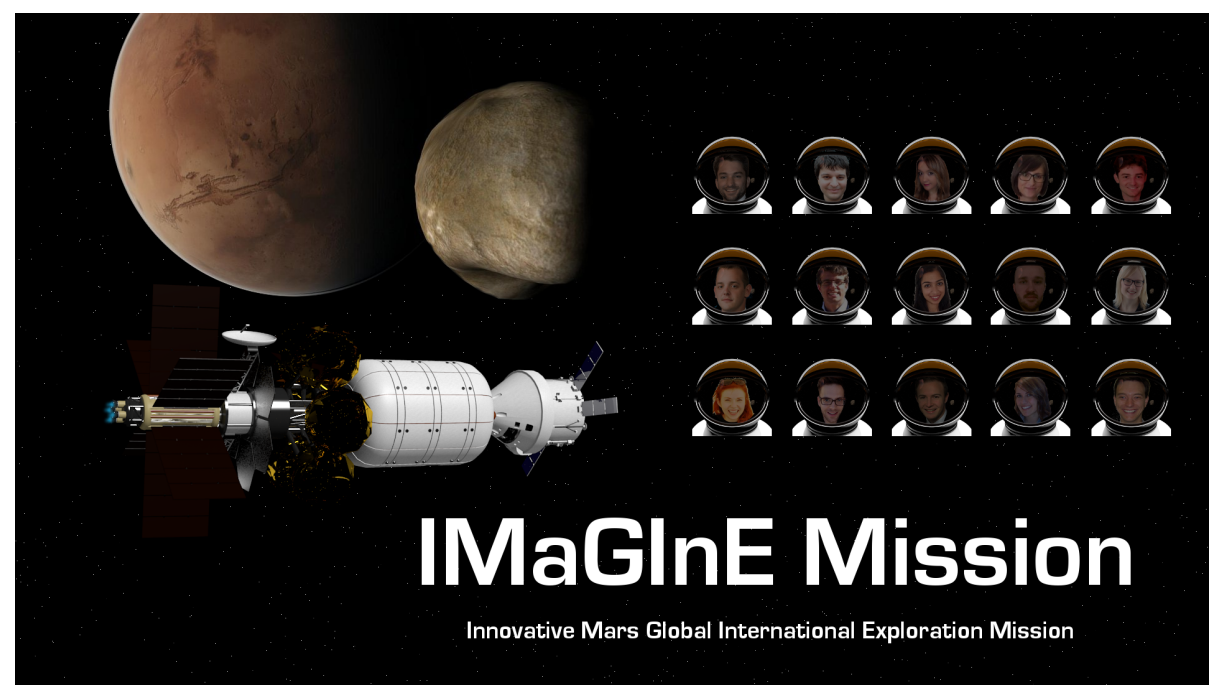

Figure F.16: Team Picture 


\section{Davide Conte}

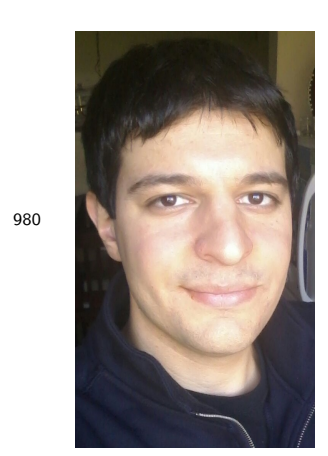

985

dynamics and mission design to help enable human exploration of Mars and beyond.

990

995

1000

Born in Italy, but currently living in the USA, Davide is a Ph.D. candidate at The Pennsylvania State University doing research in astrodynamics. He has been involved in space mission design competitions and workshops such as the Caltech Space Challenge, the ESA Moon Challenge, the Space Station Design Workshop, and RASC-AL. In his free time, Davide likes hanging out with friends, cooking, biking, and going to the gym. In the future, Davide hopes to become an engineering professor and continue his research in astro-

\section{Dorota Budzyń}

Dorota Budzyń holds an M.Eng. in Mechanical Engineering from Wrocław University of Technology and also studies Underground Mining at AGH University of Science and Technology in Kraków. She works at the European Astronaut Centre in Cologne, Germany as a Young Graduate Trainee. Her most recent project was DREAM (Drilling Experiment for Asteroid Mining) which examined the drilling output distribution in space conditions during a sounding rocket flight in March 2017. The project was done in collaboration with ESA, DLR and SSC. As a mechanical engineer, she also has experience with building robotic arms for Scorpio (Mars rovers), and some structures for FREDE (FREon Decay Experiment) which examined the disintegration of Freon in the stratosphere during its launch campaign in 2015 . 


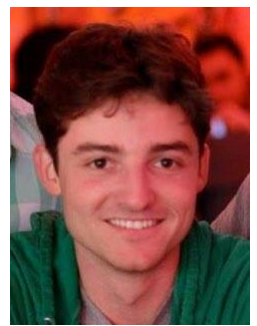

\section{Hayden Burgoyne}

Hayden Burgoyne grew up in North Hollywood, CA. He attended Harvard University, graduating in 2011 with a B.S. in Mechanical Engineering. He returned to Los Angeles to attend Caltech for graduate school and received an M.S. in 2012 and a Ph.D. in 2016. Since summer 2016, he has been the VP of Spacecraft Systems at a small space start up, Analytical Space Inc, where he oversees the design and fabrication of $6 \mathrm{U}$ CubeSats for commercial data relay missions.

1015

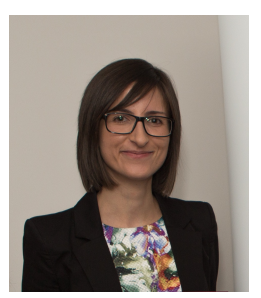

1020

1025

1030

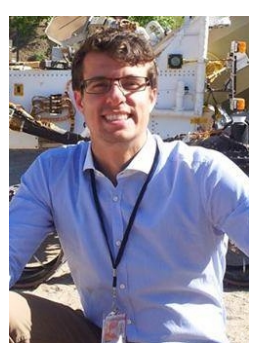

\section{Marilena Di Carlo}

Marilena received her Bachelor's and Master's degrees in Aerospace Engineering from the University of Pisa, Italy. In 2014 she received a Master's degree in Space Science and Technology from the University of Roma Tor Vergata, Italy. Since February 2014, she has been a Ph.D. candidate at the Advanced Space Concept Laboratory of the University of Strathclyde, Glasgow. Her research interests include lowthrust trajectory optimization and evolutionary computation.

\section{Dan Fries}

Born in Germany, Dan is currently pursuing a Ph.D. in Aerospace Engineering at the Georgia Institute of Technology. His work focuses on experimental research in incompressible and compressible turbulent flows and the interaction with chemical reactions. He currently serves as a member of the technical committee at the Institute for Interstellar Studies. In the past, he participated in events such as the 2015 Caltech Space Challenge, RASC-AL 2016, and the Mars Society Inspiration Mars Design competition. His personal interest is the application of cutting edge technologies to facilitate space access and concepts to utilize the immense resources of space 
sustainably.

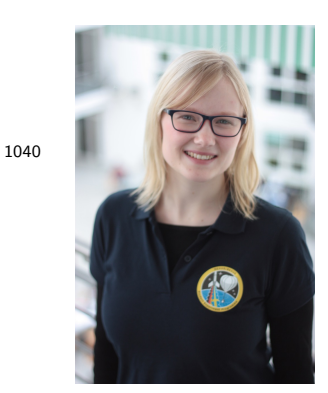

\section{Maria Grulich}

Maria grew up in Hannover, Germany and graduated with an M.S. in 2016 from the Technical University of Munich with one semester at ISAE SUPAERO, in France. She wrote her master's thesis at the Florida Institute of Technology. She has been involved in a student working group for rocket science working on the mechanical design of a $1 \mathrm{U}$ CubeSat. As a team leader, she developed a sounding rocket experiment which flew in 2015 on REXUS 18 from Kiruna, Sweden. Maria participated in several space mission design competitions and workshops such as Space Station Design Workshop and RASC-AL. Currently she is working at ESA in ESTEC as a Young Graduate Trainee in the Review Office of the Inspector General. Maria is part of the core team of Young ESA a networking group organizing field trips and events for its members.

\section{Sören Heizmann}

Sören Heizmann was born in Germany, and received his B.S. in Aerospace Engineering at the University of Stuttgart (Germany). During his studies, he worked for one and a half year at Airbus Defense and Space. Currently, he is doing a M.S. in Aerospace Engineering at the University of Stuttgart and is also attending lectures at the KTH Royal Institute of Technology (Sweden). In the past, he successfully participated in various space related student competitions such as the Inspiration Mars Society Design Competition, Space Station Design Workshop 2015 and RASC-AL 2016 where he received the PEACH Award together with his team members. His focus is on general space mission design and spacecraft propulsion. 


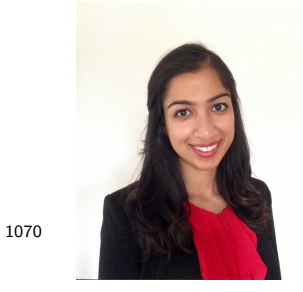

\section{Henna Jethani}

Henna received a B.S. degree in aerospace engineering at MIT and an M.S. degree in aerospace engineering at University of Colorado Boulder with a focus on bioastronautics. Henna took part in the 2015 Caltech Space Challenge, NASA eXploration Habitat (X-Hab) Academic Innovation Challenge, and RASC-AL 2016. In the past, she has had internships with Raytheon Space and Airborne Systems and NASA Johnson Space Center. Since February 2016 she has been working at Blue Origin in Seattle, Washington.

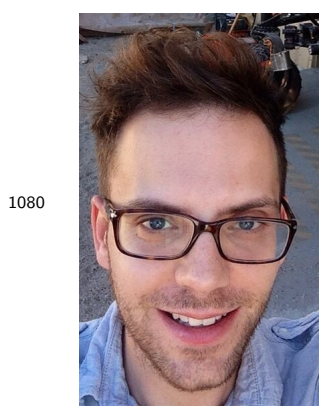

\section{Mathieu Lapôtre}

Mathieu Lapôtre is a planetary geologist and spectroscopist who studies planetary surface processes and how they can further our understanding of ancient planetary environments. He attended the University of Strasbourg, graduating with a B.S. in Geophysics (minor in Astrophysics), a M.S. in Environmental Science, and a M.S. in Geophysical Engineering. After conducting research at UC Berkeley, MIT, and Cambridge University, Mathieu enrolled at the California Institute of Technology. He graduated in 2014 with a MS in Planetary Science, and is currently a Ph.D. candidate in Geology, and a Science And Operations Team Collaborator for the NASA MSL Curiosity rover.

\section{Tobias Roos}

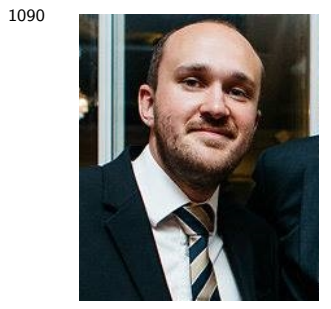

Tobias received his B.S. in Space Technology at Luleå University of Technology, Sweden, in 2011, after which he enrolled in the Erasmus Mundus Space Master Joint Programme, studying at Luleå University of Technology and Julius-MaximiliansUniversität Würzburg, Germany. He received his M.S. in Space Technology, with a focus on robotics, in 2013, and started working as Assistant Project Manager for the New 
Esrange project at Swedish Space Corporation (SSC), before shifting to his current position as a Ph.D. candidate in the Onboard Space Systems group at Luleå University of Technology. His research is focused on autonomous heterogeneous robot teams for space exploration, combining aspects of machine learning and system architecture.

\section{Encarnación Serrano Castillo}

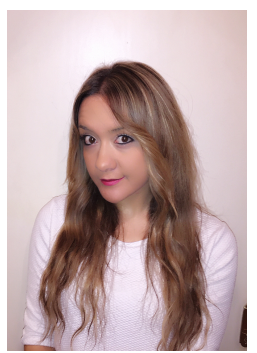

1110

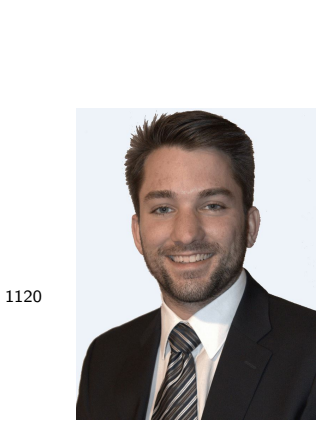

\section{Marcel Schermann}

Marcel received his B.S. and M.S. degrees in aerospace engineering at the University of Stuttgart, Germany. He is currently a young graduate trainee at ESA/ESTEC and he has worked as a trajectory design engineer at Astos Solutions. Marcel also had internships at Porsche Engineering Services and Airbus Helicopter. He took part in the Space Station Design Workshop 2015 in Stuttgart, Germany and is part of the Dream Team of the RASC-AL 2016 competition. 


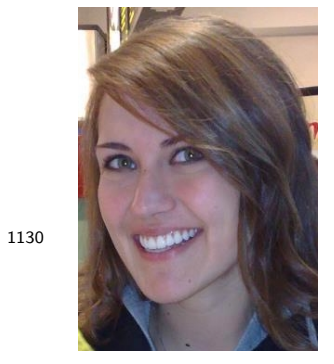

\section{Rhiannon Vieceli}

Rhiannon attended the Pennsylvania State University where she obtained a B.S. in Physics and a M.S. in Geosciences. She was then a student intern with the geophysics group at the Lawrence Livermore National Laboratory. She is now beginning her Ph.D. at the New Mexico Institute of Mining and Technology in Geosciences with a focus in seismology. She has attended several geophysical conferences, workshops, and contributed to a seismological instrument deployment. In the future she hopes to become a professional geophysics researcher either in academia or at a national laboratory.

\section{Lee Wilson}

1140

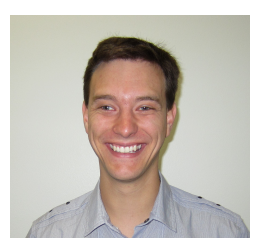

Lee started life in New Zealand and made his way to Caltech for a Ph.D. and an M.S. in Space Engineering from Caltech and a B.E. Mechanical from the University of Canterbury. He is engaged in the numerical analysis of packaging and deployment of ultra-light space structures. These structures are vital to many space systems, including deployable sunshields, inflatable habitats and solar sails. Other research interests include in-situ resource utilization of space resources, as well as spacecraft mechanical design, in particular mechanisms used by small satellites.

\section{Christopher Wynard}

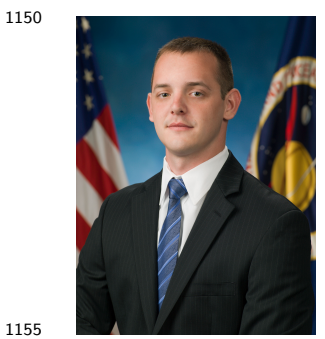

Chris received his B.S. degree in Aerospace Engineering and Business Administration at the University of Illinois at Urbana-Champaign in 2016. He did an extended co-op with NASA Johnson Space Center where he currently works as a space suit engineer. Chris took part in the 2015 Caltech Space Challenge and is part of the Dream Team of the RASC-AL 2016 competition. 